\title{
Variational Pseudo-Multiple-Doppler Wind Retrieval in the Vertical Plane for Ground-Based Mobile Radar Data
}

\author{
CHRISTOPHER C. Weiss \\ Department of Geosciences, Texas Tech University, Lubbock, Texas \\ HOWARD B. BLUESTEIN \\ School of Meteorology, University of Oklahoma, Norman, Oklahoma \\ ROBERT CONZEMIUS \\ Windlogics, Inc., Grand Rapids, Minnesota \\ Evgeni Fedorovich \\ School of Meteorology, University of Oklahoma, Norman, Oklahoma
}

(Manuscript received 5 June 2006, in final form 14 October 2006)

\begin{abstract}
A variational procedure is developed that utilizes mobile ground-based range-height indicator (RHI) Doppler radar velocity data for the synthesis of two-dimensional, RHI plane wind vectors. The radial component winds are obtained with the radar platform in motion, a data collection strategy referred to as the rolling RHI technique. Using the assumption of stationarity—standard to any pseudo-multiple-Doppler processing technique-individual radial velocity values at a given point in space will contribute a varying amount of independent information to the two components of wind velocity in the RHI plane, depending strongly on the difference in radar viewing angles amongst the looks.

The variational technique is tested successfully with observation system simulation experiments, using both a homogeneous flow field and large eddy simulation (LES) output from a highly sheared convective boundary layer simulation. Pseudoradar data are collected in these tests in a manner consistent with the specifications of the University of Massachusetts mobile W-band radar, which was used in a separate study to resolve the finescale structure of a dryline during the International $\mathrm{H}_{2} \mathrm{O}$ Project (IHOP_2002). The results of these tests indicate clearly that the technique performs well in regions of adequate "look" angle separation. Observation error contributes significantly to the analysis when the radar looks become more collinear.
\end{abstract}

\section{Introduction}

Doppler radars have long been valuable for the determination of three-dimensional winds in moistconvective phenomena, including mesoscale convective systems (e.g., Kessinger et al. 1987; Biggerstaff and Houze 1993; Braun and Houze 1994), supercell thunderstorms (e.g., Brandes 1977; Ray et al. 1980; Hane

Corresponding author address: Dr. Christopher C. Weiss, Texas Tech University-Atmospheric Science Group, Box 42101, Lubbock, TX 79409.

E-mail: Chris.Weiss@ttu.edu and Ray 1985; Johnson et al. 1987; Brandes et al. 1988; Wakimoto et al. 1996; Dowell and Bluestein 1997; Dowell et al. 1997), and tornadoes (e.g., Bluestein and Unruh 1989; Wurman and Gill 2000; Bluestein et al. 2004a; Alexander and Wurman 2005). However, considerable utility has been demonstrated in clear-air environments as well (e.g., Reinking et al. 1981; Gal-Chen and Kropfli 1984; Atkins et al. 1995; Weiss and Bluestein 2002; Bluestein et al. 2004b; Weiss et al. 2006).

Since Doppler radars sense the component of wind along the line of sight of the lobes only, the identification of nonradial components to the flow can only be 
achieved using radar looks ${ }^{1}$ from different positions (i.e., dual- or multiple-Doppler analyses), kinematic flow constraints (e.g., mass continuity), or assumptions about the shape [e.g., ground-based velocity track display (GBVTD; Lee et al. 1999)] and stationarity (e.g., Jorgensen et al. 1995) of the flow.

Dual- and multiple-Doppler analysis techniques fall primarily into two categories. The traditional methods of analysis (e.g., Ray et al. 1980; Dowell and Bluestein 1997) involve iterations among a set of equations describing the radial wind velocity measured by each radar and a form of the mass continuity equation. These techniques generally produce accurate results, but erroneous results can be generated if specific conditions on the radar viewing geometry, especially elevation angles, are not met (Ray et al. 1985; Dowell and Shapiro 2003). In these cases, the analysis problem becomes ill posed. Also, since the iterative methods involve solving for the horizontal and vertical components of the wind in a nonsimultaneous manner, residual errors can be introduced for significantly inaccurate first guesses of vertical velocity due to inconsistencies in the horizontal and vertical wind field (Bousquet and Chong 1998).

Another group of analysis techniques invoke variational calculus (Sasaki 1970) in order to analyze dualand multiple-Doppler velocity data. In these methods, a functional is created that penalizes the analysis for nonconformity to any number of constraints, including radial velocity observations, kinematic constraints, and smoothness (e.g., a Laplacian filter). The gradient of this functional with respect to the dependent analysis variables provides the information necessary to find the optimal solution, as defined by the constraints, which can individually be either strong (i.e., satisfied exactly) or weak (i.e., satisfied in a least squares sense). One main advantage of this approach is that horizontal and vertical wind components can be included in the same functional and therefore solved simultaneously. If the mass continuity equation is used as a weak constraint, then one avoids the rapid accumulation of divergence errors-and therefore vertical velocity errors-as a consequence of direct integration of the mass continuity equation (Gao et al. 2004). Typically, mass continuity is not used as a strong constraint as second-order partial differential equations must be solved (Shapiro and Mewes 1999). Since variational techniques do not suffer from the ill posedness mentioned above, there is

\footnotetext{
${ }^{1}$ In this paper, the term "radar look" will be used to denote a sample of radial wind velocity by the radar at a viewing angle referred to as the "radar look angle."
}

no elevation angle restriction on data that can be incorporated.

When only one radar is present, pseudo-dualDoppler techniques can be used to synthesize the wind field. The central assumption made is that of stationarity, that is, the wind field does not change appreciably between the two looks of the same radar. The validity of this assumption depends on the scan rate and scan strategy of the radar. Considering the example of the National Center for Atmospheric Research (NCAR) Electra fore-aft scanning technique (Jorgensen et al. 1995), the time between the looks of each radar is a monotonic function of range from the aircraft. Therefore, the stationarity approximation is most accurate close to the aircraft.

Presented here is a new variational pseudo-multipleDoppler technique that, when applied to range-height indicator (RHI) data taken with a mobile platform, can synthesize the two-dimensional wind field in the plane of the RHIs. The knowledge of such wind fields can be useful, for example, for identifying the vertical structure of, and secondary circulation normal to, atmospheric boundaries (e.g., drylines, fronts, outflow boundaries), as well as determining vertical wind profiles in the synoptically inactive convective boundary layer. In Weiss et al. (2006) (Fig. 1), this technique is applied to data obtained with the University of Massachusetts W-band radar to resolve the frontogenetical solenoidal circulation about a double-dryline event in the Oklahoma Panhandle during the International $\mathrm{H}_{2} \mathrm{O}$ Project (IHOP_2002; Weckwerth et al. 2004). The tests in this study are carefully designed to mimic the characteristics of this W-band radar, though the results can be applied broadly to any platform. In section 2 the variational technique is developed, including a description of the data collection strategy needed. The technique is tested with a series of observation system simulation experiments (OSSEs) in section 3. A summary and conclusions are provided in section 4 .

\section{Development of the technique}

\section{a. Data collection strategy}

The variational technique developed below requires radar data that are collected with the rolling RHI technique. RHIs are often used to identify quickly the vertical structure of atmospheric phenomena. Much of the same mechanics are involved in rolling RHI collection; the antenna is rotated repeatedly from the horizon to the local zenith and back. However, the platform is in motion during the data collection, permitting any arbi- 
a)
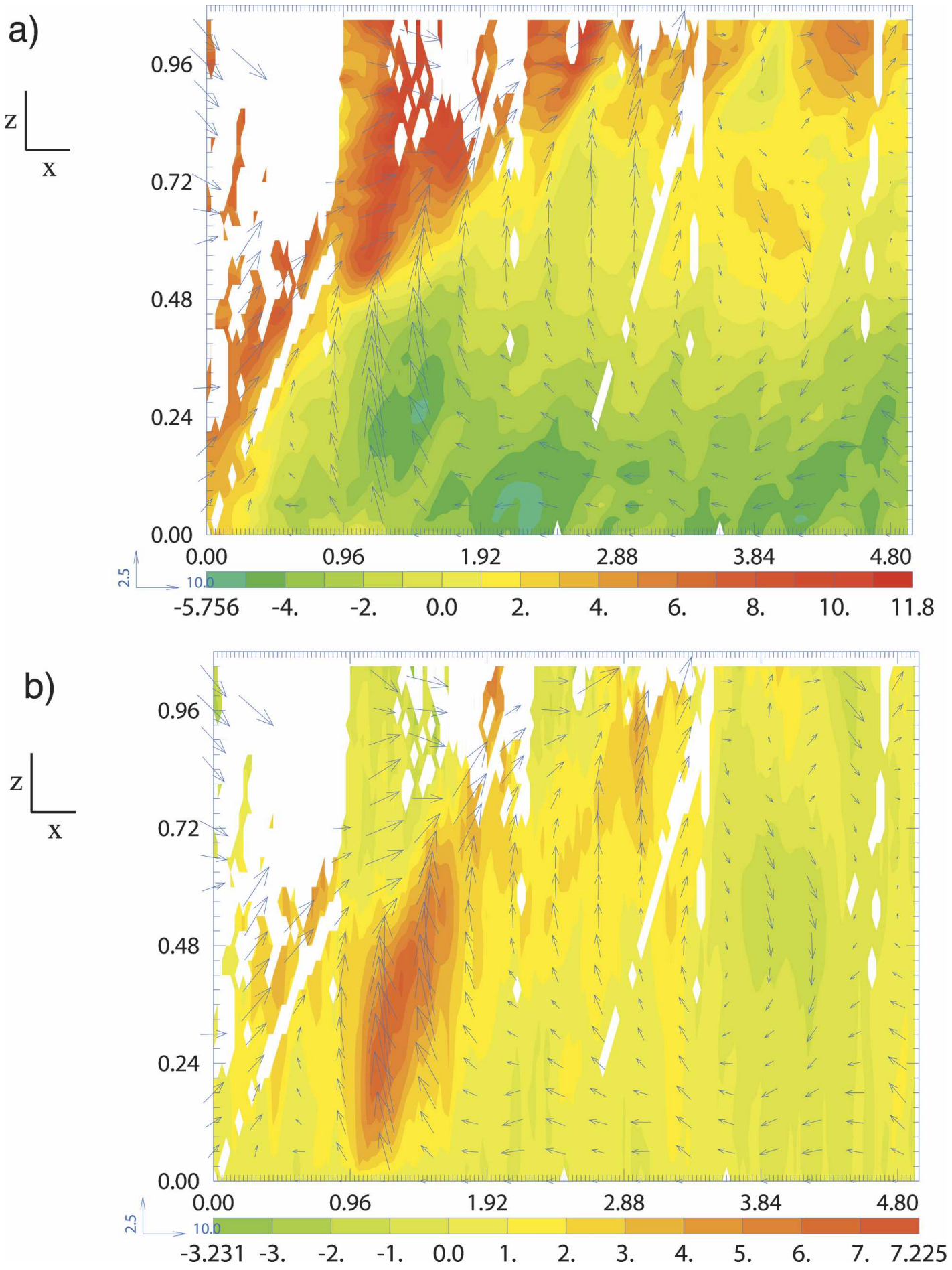

FIG. 1. (a) The $u$-component velocity (shaded; $\mathrm{m} \mathrm{s}^{-1}$ ) and (b) vertical velocity (shaded; $\mathrm{m} \mathrm{s}^{-1}$ ) along the head of a retreating dryline. The $u / w$ wind vectors are overlaid in both figures. Distance scales $(\mathrm{km})$ are provided (from Weiss et al. 2006). 

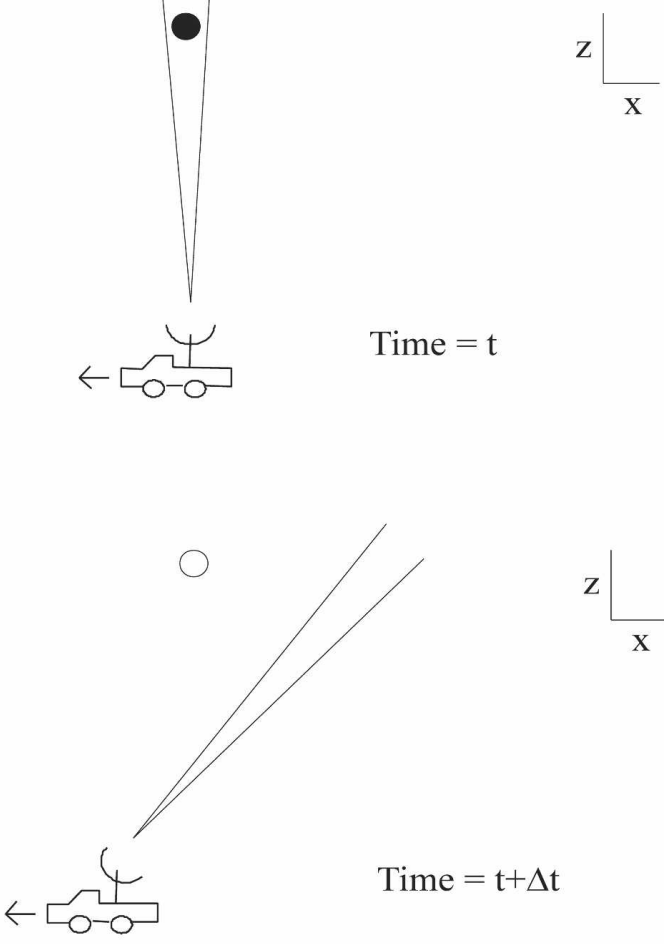

Time $=\mathrm{t}$

Time $=\mathrm{t}+\Delta \mathrm{t}$
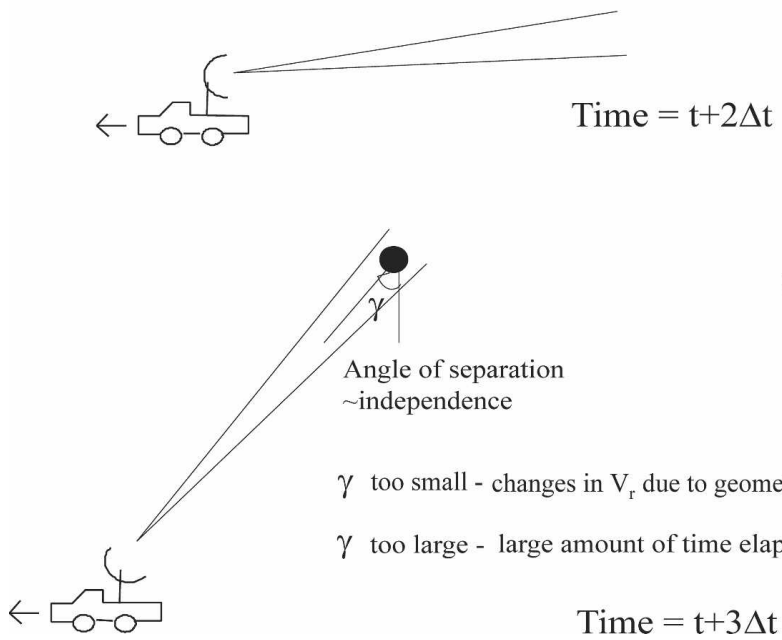

$\mathrm{Z}$

Angle of separation

$\mathbf{X}$

rindependence

$\gamma$ too small - changes in $\mathrm{V}_{\mathrm{r}}$ due to geometry $<$ observational error

$\gamma$ too large - large amount of time elapsed, stationarity assumption questionable

Time $=\mathrm{t}+3 \Delta \mathrm{t}$

FIG. 2. A schematic of rolling RHI method of data collection. The black dot represents an arbitrary point in space that is sampled by the radar from two separate look angles. 
trary point in the atmosphere above to be viewed from more than one look angle (Fig. 2). The density of radar looks is a function of the platform speed and scan rate and varies widely across the domain.

A constant platform speed was desired to minimize the error in platform velocity subtraction from the measured Doppler winds, which relies on discrete GPS position samples (see appendix).

\section{b. Derivation of Euler-Lagrange equations}

Variational analyses can be constructed to satisfy any number of observational and kinematic constraints. Possible constraints considered for these analyses include radial velocity observations, mass continuity, and smoothness. The smoothness constraint was eliminated in the development of this technique for a couple of reasons. First, using gridpoint spacing comparable to the native resolution of the radar data, a prescribed smoothness constraint (in practice, usually a Laplacian operator) would counter the benefits of the very fine spatial resolution afforded by a high-frequency radar [e.g., the University of Massachusetts (UMass) W-band radar used in Weiss et al. (2006)]. In other words, this smoothness constraint would potentially eliminate small scales of motion that were indeed real and resolvable. Furthermore, the mass continuity constraint already contains the properties of a low-pass filter, as uncoupled errors in $u$ and $w$ are diminished. Therefore, a second mechanism for smoothing was deemed redundant and unnecessary.

Radial velocity observations and mass continuity were imposed as weak constraints in this formulation. A strong constraint on mass continuity was avoided, as the observations were deemed highly reliable, owing to the significant amount of overlap; furthermore, weak constraint formulations have been found to be more accurate than strong constraint formulations in pseudodual-Doppler analyses of thunderstorms (Dowell and Bluestein 2002).

Following the specifications above, the cost function to be minimized was

$$
\begin{aligned}
J & =\sum_{\text {domain }}\left(J_{O}+\beta J_{C}\right), \\
J_{O} & =\sum_{n=1}^{m(x, z)}\left(c_{1}^{n} u+c_{2}^{n} w-V_{r}^{n}\right)^{2}, \\
J_{C} & =(\partial u / \partial x+\partial w / \partial z+\kappa w)^{2},
\end{aligned}
$$

$$
\begin{aligned}
& c_{1}=\cos \left(\alpha^{n}\right), \quad \text { and } \\
& c_{2}=\sin \left(\alpha^{n}\right),
\end{aligned}
$$

where (1b) represents the contribution to the cost function from observational increments and (1c) denotes the contribution to the cost function from anelastic mass continuity violation. In (1a)-(1e) $u$ and $w$ represent the analysis values; $V_{r}$ is the radial velocity of observation $n ; c_{1}$ and $c_{2}$ represent geometric coefficients mapping velocities from Cartesian space to that of the radial velocity vectors; $\kappa$ is the correction to mass continuity for vertical density stratification (calculated using a dry adiabatic lapse rate in the boundary layer); $m$ is the total number of observations per grid point, of which $n$ is a specific observation; and $\alpha^{n}$ is the look angle for each observation $n$. The formulation is similar to that developed by Gao et al. (1999) and Dowell and Bluestein (2002), though inherently designed for pseudo-Doppler wind synthesis using the multiple-radar looks afforded by the rolling RHI technique described in section $2 \mathrm{a}$.

The $\beta$ term in (1a) represents the relative weight given to mass continuity violation and observation increments in the calculation of the cost function. In the spirit of a statistically optimal analysis, $\beta$ would be dependent on the relative spatial error variance characteristics of the radial velocity observations and the mass continuity constraint. In many cases, however, we do not know the spatial error characteristics of the radar. Therefore, the $\beta$ term is a more arbitrary assignment of the relative importance of the two constraints. A higher value of $\beta$ denotes a larger penalty for anelastic mass continuity violation, which may be desired when using observations with larger errors. Likewise, a smaller value of $\beta$ weights more the penalty for analysis grid points that deviate from the observations of radial velocity. For the units of each constraint to be consistent $\left(\mathrm{m}^{2} \mathrm{~s}^{-2}\right)$, it is necessary for $\beta$ to have units of meters squared. A logical choice of length scale (following Dowell and Bluestein 2002) was the grid spacing of the analysis. It was therefore deemed appropriate to assign

$$
\beta=(\Delta x)^{2}=(\Delta z)^{2} .
$$

Since the grid spacing used for this analysis was $\Delta x=$ $\Delta z=30 \mathrm{~m}, \beta$ was chosen to be $900 \mathrm{~m}^{2}$.

The derivation of the weak constraint variational formulation follows. We start with the statement of the cost function 


$$
J=\iint_{x z}\left[\sum_{n=1}^{m(x, z)}\left(c_{1}^{n} u+c_{2}^{n} w-V_{r}^{n}\right)^{2}+\beta(\partial u / \partial x+\partial w / \partial z+\kappa w)^{2}\right] d x d z
$$

Taking the variation of $J$ with respect to $u$ and equating this expression to zero yields

$$
\delta_{u} J=\iint_{x z}\left[2 \sum_{n=1}^{m(x, z)}\left(c_{i}^{n} u+c_{2}^{n} w-V_{r}^{n}\right) c_{1}^{n} \delta u+2 \beta(\partial u / \partial x+\partial w / \partial z+\kappa w) \partial / \partial x(\delta u)\right] d x d z=0 .
$$

The second term in (3) is integrated by parts to become

$$
\left.\int_{z} \beta(\partial u / \partial x+\partial w / \partial z+\kappa w) \delta u\right|_{x_{\text {west }}} ^{x_{\text {east }}} d z-\iint_{x z} \delta u \partial / \partial x[\beta(\partial u / \partial x+\partial w / \partial z+\kappa w)] d x d z .
$$

The first term of (4) requires specific information at the boundaries of the analysis domain. We can eliminate this term by satisfying anelastic mass continuity exactly on the lateral boundaries. The reduced version of (3) then appears as

$$
\iint_{x z}\left[\sum_{n=1}^{m(x, z)}\left(c_{1}^{n} u+c_{2}^{n} w-V_{r}^{n}\right) c_{1}^{n}-\beta \partial / \partial x(\partial u / \partial x+\partial w / \partial z+\kappa w)\right] \delta u d x d z=0 .
$$

Distributing the summation and discounting the trivial solution of $\delta u=0,(5)$ can only be true when

$$
\sum_{n=1}^{m(x, z)}\left(c_{1}^{n}\right)^{2} u+\sum_{n=1}^{m(x, z)}\left(c_{1}^{n} c_{2}^{n}\right) w-\sum_{n=1}^{m(x, z)}\left(c_{1}^{n} V_{r}^{n}\right)=\beta \partial / \partial x(\partial u / \partial x+\partial w / \partial z+\kappa w) .
$$

Equation (6) represents one of the Euler-Lagrange equations. The other Euler-Lagrange equation can be found in a similar manner by taking the variation of (2) with respect to $w$ :

$$
\sum_{n=1}^{m(x, z)}\left(c_{1}^{n} c_{2}^{n}\right) u+\sum_{n=1}^{m(x, z)}\left(c_{2}^{n}\right)^{2} w-\sum_{n=1}^{m(x, z)} c_{2}^{n} V_{r}^{n}=\beta(-\kappa+\partial / \partial z)(\partial u / \partial x+\partial w / \partial z+\kappa w)
$$

There are a number of different methods for finding the optimal solution with knowledge of $\nabla_{u, w} J$ (e.g., steepest descent, conjugate gradient). The preferred method for solution here (after Dowell and Bluestein 2002) is a numerical iteration of the two Euler-Lagrange equations, discretized using centered differencing:

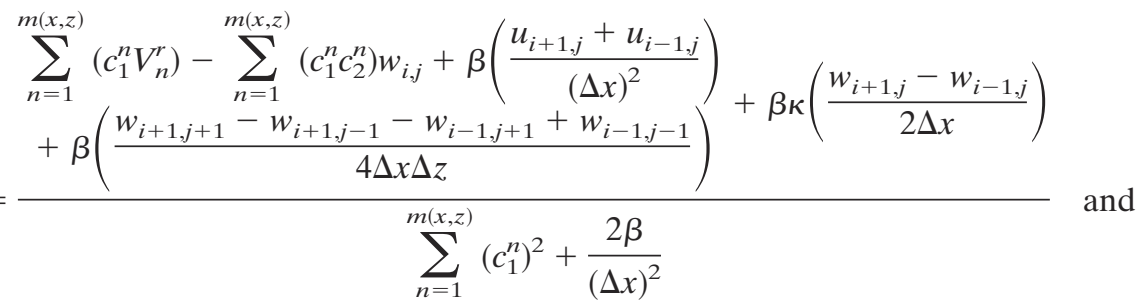




$$
w_{i, j}=\frac{\sum_{n=1}^{m(x, z)}\left(c_{2}^{n} V_{r}^{n}\right)-\sum_{n=1}^{m(x, z)}\left(c_{1}^{n} c_{2}^{n}\right) u_{i, j}+\beta\left(\frac{u_{i+1, j+1}-u_{i-1, j+1}-u_{i+1, j-1}+u_{i-1, j-1}}{4 \Delta x \Delta z}\right)-\beta \kappa\left(\frac{u_{i+1, j}-u_{i-1, j}}{2 \Delta x}\right)}{+\beta\left(\frac{w_{i, j+1}+w_{i, j-1}}{(\Delta z)^{2}}\right)}
$$

The technique developed here applies to flows that are primarily two dimensional. In such flows, the transverse plane wind convergence (inherently not measurable) is negligible in comparison to the in-plane wind convergence; as such, the two-dimensional form of the anelastic mass continuity equation is appropriate. When sampling atmospheric convergence boundaries (e.g., fronts, drylines), the technique will perform best for traverses normal to the convergence line. For situations where transverse wind convergence is not negligible (a 3D flow), a smoothness constraint may be more appropriate than mass continuity.

\section{c. Method of solution}

A layer of extra grid points was added outside of the domain to permit calculations of first- and second-order derivatives on the boundary. For each iteration of the solution process, the exterior grid points were updated to enforce the boundary conditions. Along the lower boundary, the impermeability condition was applied. For the rest of the boundaries, mass continuity was required to be satisfied exactly. Since the spacing of the grid points was comparable to the resolution of the velocity data, the velocity data were assigned to the nearest grid point for analysis.

The optimal solution was found in the following manner.

1) The domain was initialized with a first guess of the analysis ( $u=w=0$ was used by default in this case).

2) Equation (8) was applied to update the analysis value $u$ for the entire domain, from left to right and from bottom to top.

3) Equation (9) was used to update the analysis value $w$ in the same manner.

4) The top and side boundary conditions were updated.

5) The cost function $J$ was calculated for the analysis.

6) If the reduction in cost function from the iteration was not below a prescribed tolerance, steps 2 through 5 were repeated.

In our experiments, the above procedure largely allowed for convergence to a unique optimal solution, regardless of the choice of first guess. However, an analysis bias toward the first guess was noted in regions with limited differences in look angle (this bias is discussed in section 3 ).

\section{Observation system simulation experiments}

A series of OSSEs was developed to test the variational analysis method by comparing analysis values to known "true" values. For each OSSE, a prescribed flow field was sampled with a "pseudoradar" using various rolling RHI strategies. The result of this operation was a time series of simulated radial velocity data, which was used in conjunction with the variational analysis technique to produce an analysis of $u$ and $w$ velocity in the two-dimensional plane of the radar motion. Error statistics were calculated by comparing the experimental analyses to the true field, from which the radial velocity observations were derived.

\section{a. Homogeneous flow case with perfect observations}

A uniform horizontal flow field of $u=10 \mathrm{~m} \mathrm{~s}^{-1}$ was the first to be sampled with the pseudoradar. The rolling RHI scanning strategy was employed. For the control simulation, a platform velocity of $15 \mathrm{~m} \mathrm{~s}^{-1}$ and a vertical antenna rotation rate (hereafter scan rate) of $1.5^{\circ} \mathrm{s}^{-1}$ were used. ${ }^{2}$ Pseudodata were assumed to be error free and were stored at $10 \mathrm{~Hz}$ in accordance with the specifications of the signal processor in the UMass $\mathrm{W}$-band radar system. A first guess of $u=w=0$ was used for all syntheses.

For the early iterations of the analysis, there was a very sharp decrease in the cost function (Fig. 3). Since the cost function is quadratic, this evolution of $J$ was expected. As the analysis approached the optimal solution, the decrease in cost function decelerated considerably. For a strict tolerance of $1.0 \mathrm{~m}^{2} \mathrm{~s}^{-2}, 125$ iterations of (8) and (9) were required for convergence in this control simulation; however, a reasonably accurate

\footnotetext{
${ }^{2}$ These parameters mimic the scanning strategy used on a real dryline case (Weiss et al. 2006).
} 


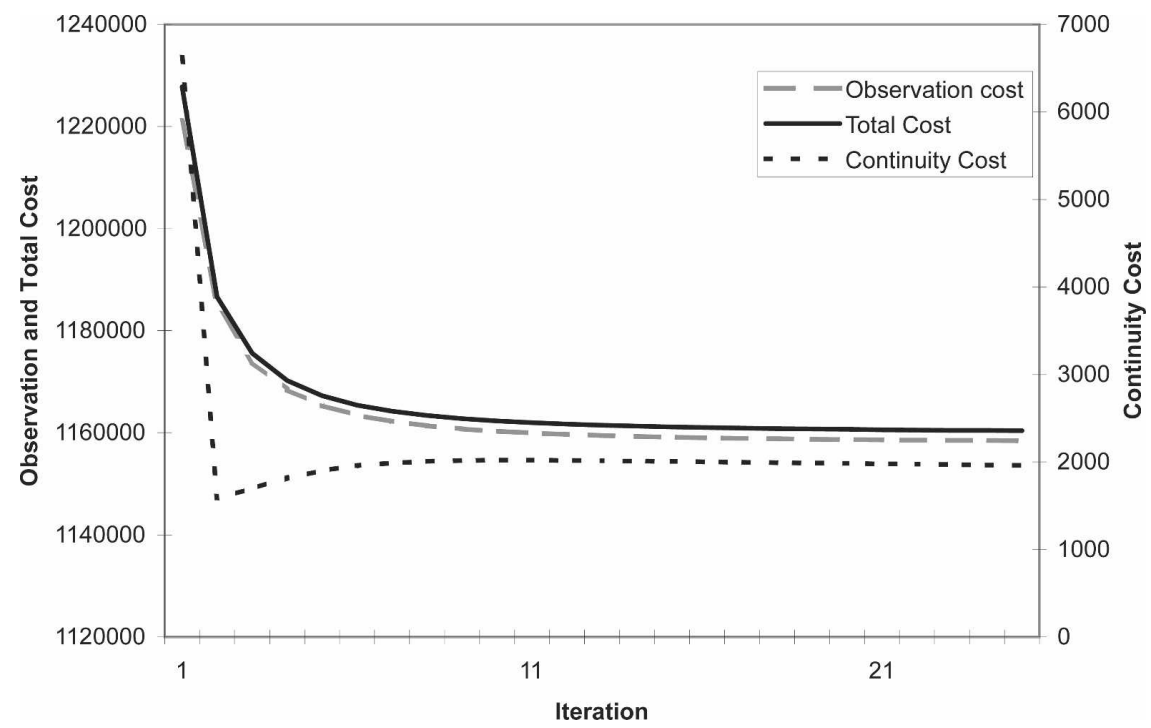

FIG. 3. Cost function $\left(\mathrm{m}^{2} \mathrm{~s}^{-2}\right)$ contribution of observational and continuity error, and total cost function for the first 25 iterations of the homogeneous flow OSSE. The platform velocity is $15 \mathrm{~m} \mathrm{~s}^{-1}$ and the scan rate is $1.5^{\circ} \mathrm{s}^{-1}$.

analysis could have been achieved in as few as five iterations (Fig. 3).

The results from this experiment show that the technique successfully reproduced the constant horizontal flow field with very little error (Fig. 4). The RMS error ${ }^{3}$ for the domain was $0.12 \mathrm{~m} \mathrm{~s}^{-1}$, which was comparable to the error of the "perfect" observations. The departures from zero error are attributed to small errors in the assignment of radial velocity to grid points (section 2c).

\section{b. Homogeneous flow case with observational error}

Observational error is present in all measurement platforms. Examples of error sources include instrument noise (e.g., thermal noise), beam spreading, ducting, sidelobe contamination, among others. To simulate the effect of instrument error, a Gaussian (i.e., normal and random) error was added to the observations. In this experiment, the standard deviation of the added error was $1.0 \mathrm{~m} \mathrm{~s}^{-1}$, which is equivalent to the error characteristics of the UMass radar (A. Pazmany 2003, personal communication).

A simulation was performed with the control scanning parameters (as in section 3a). The $u$-component analysis (Fig. 5a) is very accurate over most of the domain. The largest errors are found near the top of the

\footnotetext{
${ }^{3}$ All RMS error values in this study are a total of the $u$ and $w$ components. RMS error is calculated against a reference field with no observational error applied.
}

domain, where maximum look angle differences are less than $10^{\circ}$ (Fig. 5b). In these subcritical regions, the radial velocity observations are nearly collinear. Therefore, the accuracy of the retrieval of the individual components of motion $(u, w)$ is less certain, as the variance in radial velocity due to the shifts in look angle are comparable in magnitude to the prescribed observational error. The resulting analysis has a $u$ component that is too weak compared to the true $u$-component wind in the subcritical regions. If the first guess for the analysis is changed to $u=20.0 \mathrm{~m} \mathrm{~s}^{-1}$ (from $u=0$ $\mathrm{m} \mathrm{s}^{-1}$ ), the analysis $u$-component error has identical magnitude but is of the opposite sign (i.e., the $u$ component is too strong). Therefore, it is apparent that the departure of observations from the analysis in each iteration (hereafter the innovation) is underapplied in regions with subcritical look angle differences, and the resulting analysis is therefore closer to the first guess.

Due to the nature of the rolling RHI scanning strategy, regions with large look angle differences also have a higher number of observations (Fig. 6). Therefore, since the applied observation error is random, this error should be expected to contribute less impact as more of these observations are included in the synthesis.

Multiple simulations were performed to test the sensitivity of the analysis RMS error to the scanning strategy of the hypothetical UMass radar (Fig. 7). The platform velocity was varied from 5 to $30 \mathrm{~m} \mathrm{~s}^{-1}$, while the scan rate varied from 1.0 to $10.0^{\circ} \mathrm{s}^{-1}$. The plot of RMS error reveals an increase in RMS error as the platform velocity is increased. The increase in RMS error is at- 


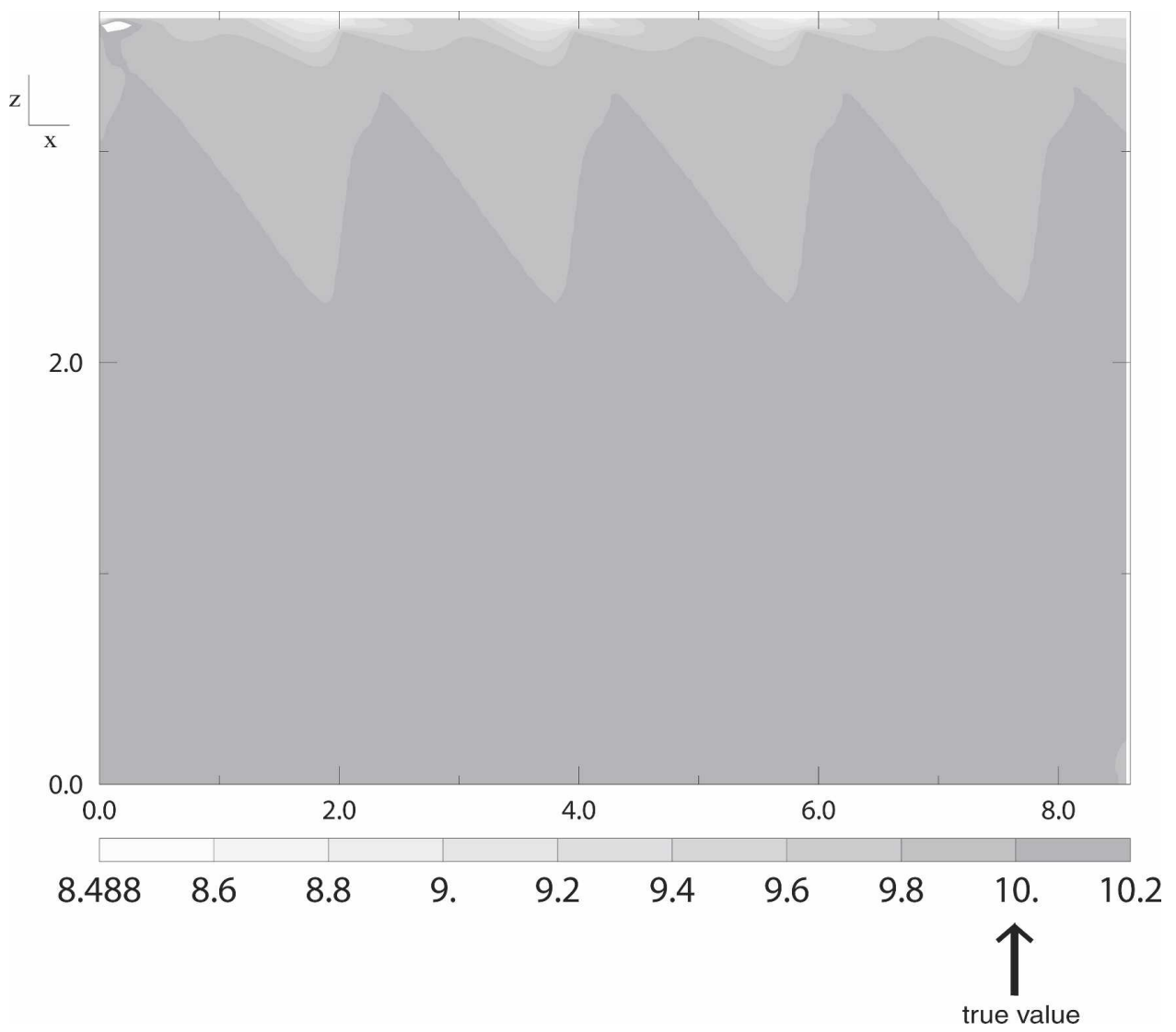

FIG. 4. The $u$-component wind velocity (shaded; $\mathrm{m} \mathrm{s}^{-1}$ ) from a homogeneous flow OSSE with a platform velocity of $15 \mathrm{~m} \mathrm{~s}^{-1}$, a scan rate of $1.5^{\circ} \mathrm{s}^{-1}$, and no observational error. Distance labels $(\mathrm{km})$ are provided on each axis.

tributed to the expansive area of subcritical look angle differences in the domain (Fig. 8). Further, if the scan rate is too slow, holes appear in the analysis due to a lack of radar coverage. In these data-void regions the first guess is altered only by information that spreads in (via spatial gradients contained in the cost functional) from neighboring data-rich regions with each analysis iteration. While the impact of platform velocity is clear, practical concerns about the expected time scale of evolution must be considered. To elaborate, slow platform translation allows for large look angle differences (ideal for observation independence), but the time spanning the looks is greater, making the stationarity assumption less accurate. In practice, these concerns about stationarity must be weighed against the potential negative effects of collinearity.

\section{c. Large eddy simulation test case}

It was desirable to test how the variational synthesis technique performed in regions with strong gradients in wind direction and velocity, similar to the environment near atmospheric boundaries. To this end, an OSSE was developed using output from a large eddy simulation (LES). This LES, which used the same code as in Conzemius and Fedorovich (2006), depicted the threedimensional structure of a highly sheared convective boundary layer $(\mathrm{CBL})$. The horizontally averaged wind and potential temperature fields in the simulations were initialized with data from rawinsonde observation taken at Dodge City, Kansas (DDC), and Amarillo, Texas (AMA), at 1200 UTC on the morning of 22 May 2002, the same date on which UMass radar data were obtained on a dryline in the eastern Oklahoma Panhandle (Weiss et al. 2006). Additionally, surface heat flux data from IHOP_2002 measurements, taken in the Oklahoma and Texas Panhandles, were used as a lower boundary condition in the LES, and the heat flux was varied in time as in the IHOP_2002 data. The grid was $256 \times 256 \times 133$ with grid cell dimensions $\Delta x=\Delta y=$ $\Delta z=30 \mathrm{~m}$. After the initialization, the CBL was allowed to develop for several hours before velocity data were extracted from the grid.

Plan views of $u$ at $90 \mathrm{~m} \mathrm{AGL}$ and $w$ at $900 \mathrm{~m} \mathrm{AGL}$ 

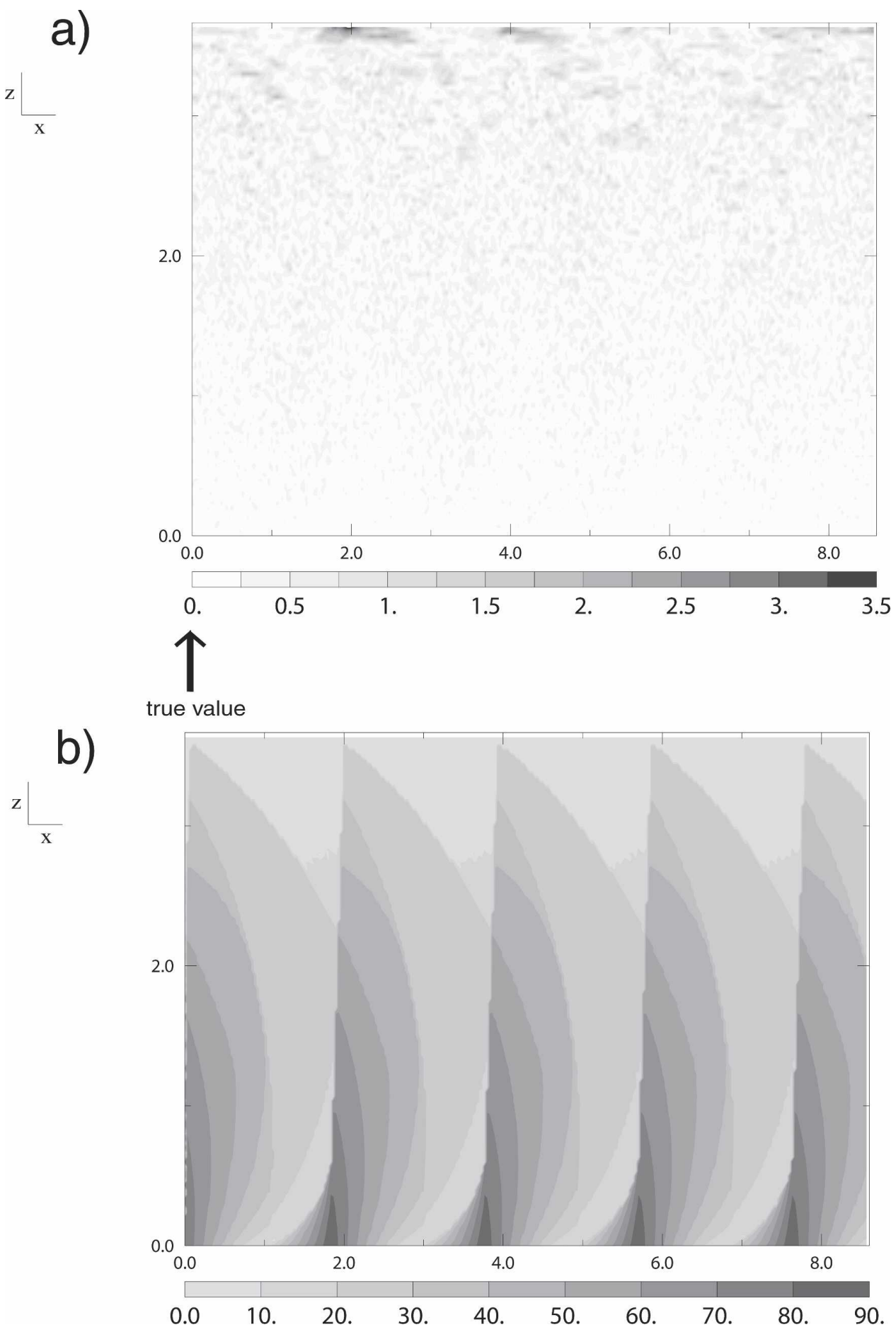

FIG. 5. (a) The $u$-component absolute wind velocity error (shaded; $\mathrm{m} \mathrm{s}^{-1}$ ) and (b) maximum look angle difference (shaded; ${ }^{\circ}$ ) from a homogeneous flow OSSE with a platform velocity of $15 \mathrm{~m} \mathrm{~s}^{-1}$, a scan rate of $1.5^{\circ} \mathrm{s}^{-1}$, and an applied random observational error with a standard deviation of $1.0 \mathrm{~m} \mathrm{~s}^{-1}$. Distance labels $(\mathrm{km})$ are provided on each axis. 


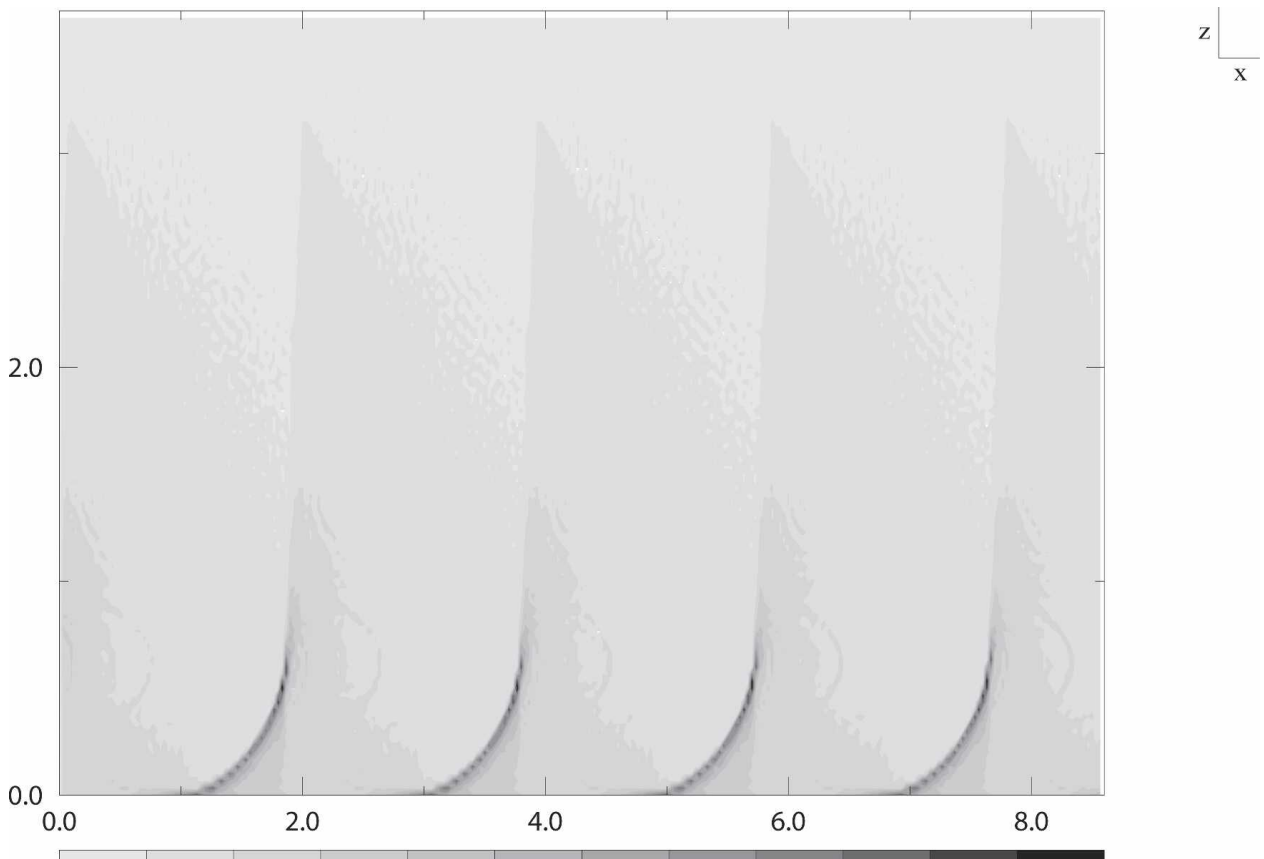

0.0 25. 70. 115. 160. 205. 250. 295. 340. 385. 430. 475. 520.

FIG. 6. Look count (shaded) from a homogeneous flow OSSE with a platform velocity of $15 \mathrm{~m} \mathrm{~s}^{-1}$ and a scan rate of $1.5^{\circ} \mathrm{s}^{-1}$. Distance labels $(\mathrm{km})$ are provided on each axis.

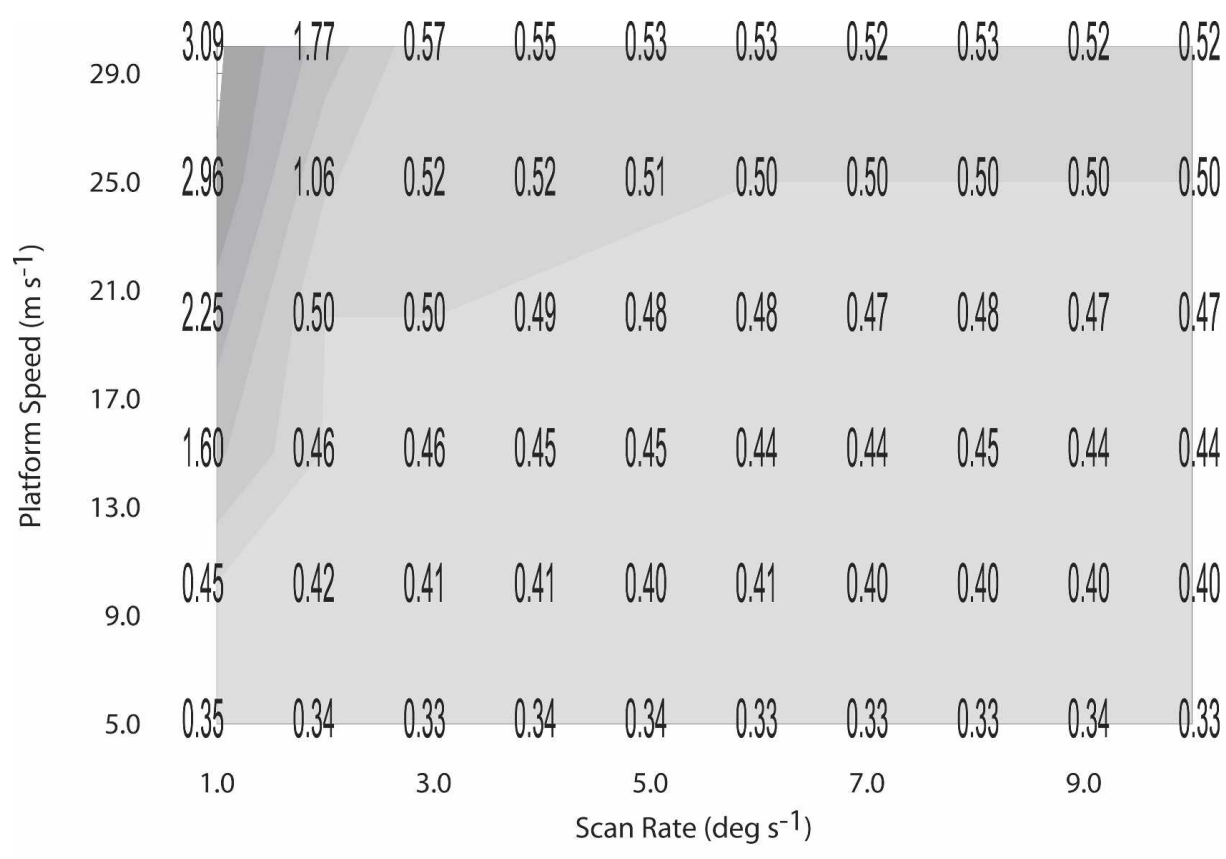

$\begin{array}{lllllll}0.0 & 0.5 & 1 . & 1.5 & 2 . & 2.5 & 3 .\end{array}$

FIG. 7. Total RMS error (shading; $\mathrm{m} \mathrm{s}^{-1}$ ) of the synthesized wind for the homogeneous flow OSSE as a function of platform velocity $\left(\mathrm{m} \mathrm{s}^{-1}\right)$ and scan rate $\left({ }^{\circ} \mathrm{s}^{-1}\right)$. Specific RMS error values are included. A random error with standard deviation $1.0 \mathrm{~m} \mathrm{~s}^{-1}$ was applied to radial velocity data for these simulations. 

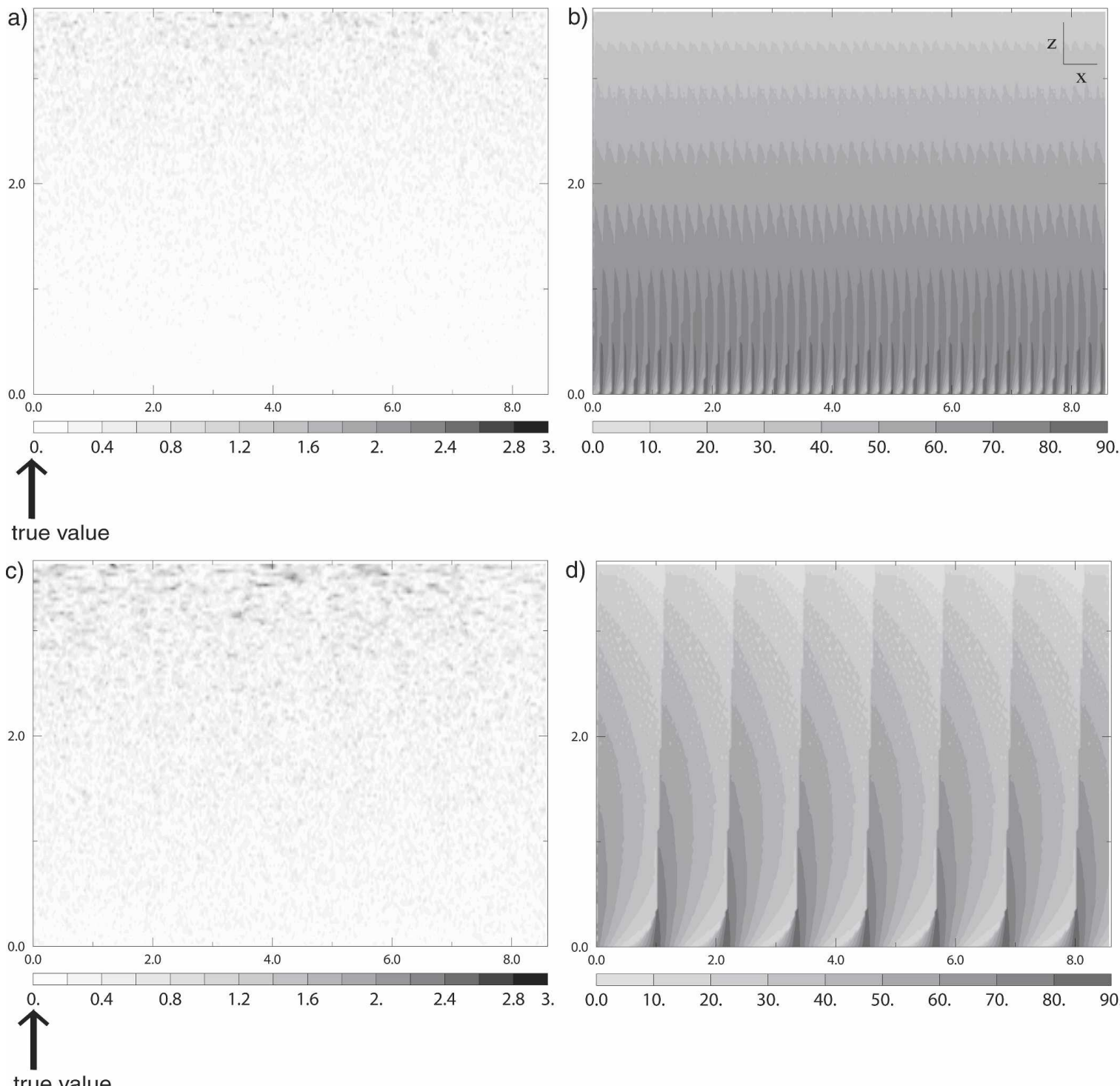

FIG. 8. (a) The $u$-component absolute wind velocity error (shaded; $\mathrm{m} \mathrm{s}^{-1}$ ) and (b) maximum look angle difference (shaded; ${ }^{\circ}$ ) from a homogeneous flow OSSE with a platform velocity of $5 \mathrm{~m} \mathrm{~s}^{-1}$ and a scan rate of $5.0^{\circ} \mathrm{s}^{-1}$. (c), (d) Same as in (a) and (b), but for a platform velocity of $30 \mathrm{~m} \mathrm{~s}^{-1}$ and a scan rate of $5.0^{\circ} \mathrm{s}^{-1}$. All simulations have an applied random observational error with a standard deviation of $1.0 \mathrm{~m} \mathrm{~s}^{-1}$. Distance labels $(\mathrm{km})$ are provided on each axis.

(Fig. 9) show clearly a southwest-to-northeast-oriented axis of convergence and upward motion in the center of the domain. The two-dimensional nature of this convection and the orientation of the axis parallel to the mean boundary layer wind suggest that this feature is a horizontal convective roll (HCR; LeMone 1973; Weckwerth et al. 1997; Atkins et al. 1998). It is noted that this feature had a very similar orientation to the dryline of 22 May 2002 (Weiss et al. 2006). Maximum upward motion is slightly over $6 \mathrm{~m} \mathrm{~s}^{-1}$ along the southern section of this HCR.

An east-west vertical cross section is plotted across the LES domain to reveal the vertical structure of the HCR (Fig. 10). Upward motion in the HCR extends to approximately $1.5 \mathrm{~km} \mathrm{AGL}$ and is about $1 \mathrm{~km}$ wide. Weaker regions of generally subsiding air extend over the remainder of the domain. The LES output served as the "truth" for a series of OSSEs and was sampled by the UMass pseudoradar utilizing the rolling RHI strategy as in previous sections.

As with the homogenous flow case, the control simulations used a platform translation speed of $15 \mathrm{~m} \mathrm{~s}^{-1}$, antenna scan rate of $1.5^{\circ} \mathrm{s}^{-1}$, and an observational error standard deviation of $1.0 \mathrm{~m} \mathrm{~s}^{-1}$. The discretized Eu- 
a)
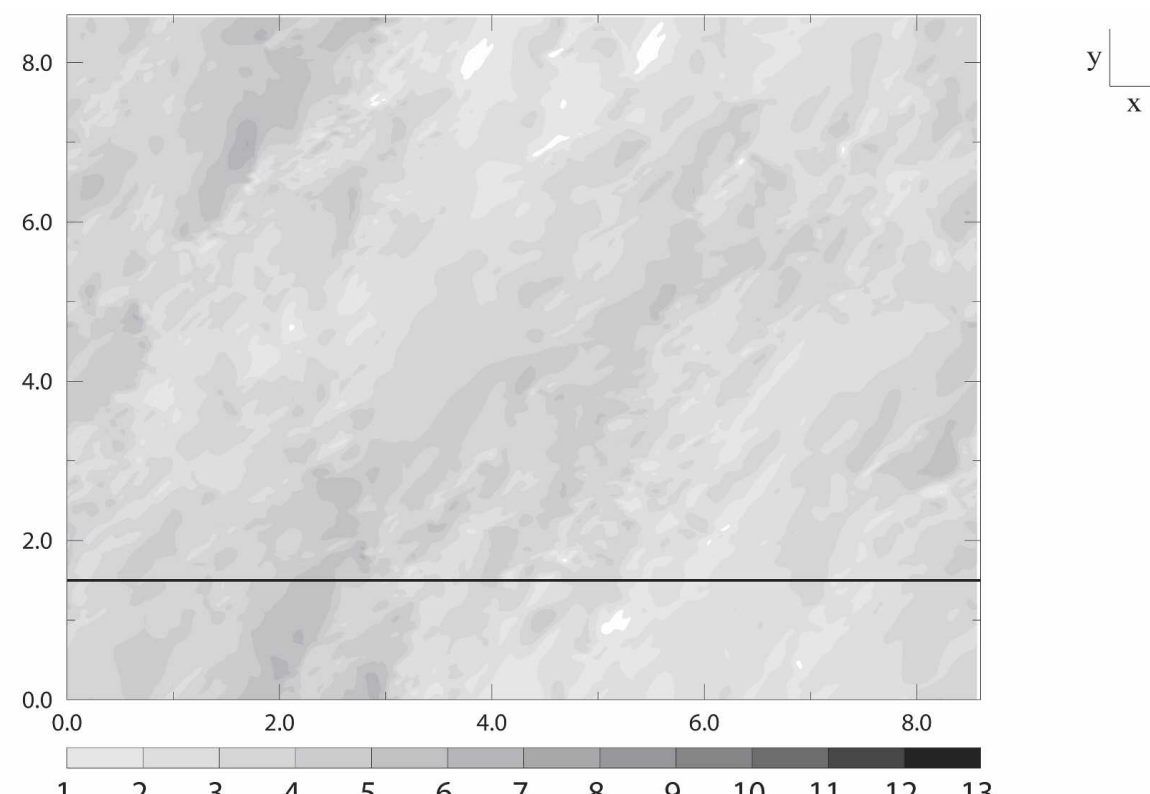

1. 2. 3. 4. 5. 6. $\quad$ 7. $\quad$ 8. $\quad$ 9. 10.11 .12 .13$.

b)
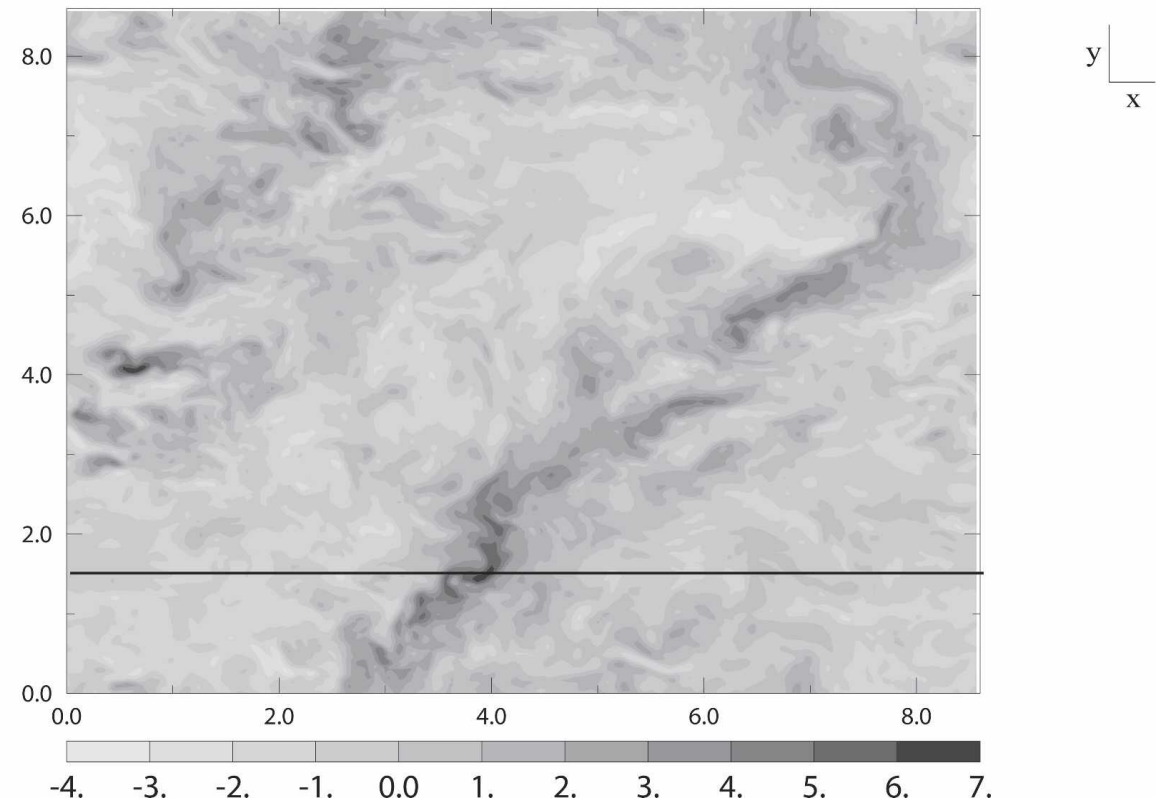

FIG. 9. (a) A 30-m AGL $u$-component wind velocity (shaded; $\mathrm{m} \mathrm{s}^{-1}$ ) and (b) a 900-m AGL vertical velocity (shaded; $\mathrm{m} \mathrm{s}^{-1}$ ) from the large eddy simulation of a highly sheared convective boundary layer. The black line denotes the plane of cross section for Fig. 10. Distance labels $(\mathrm{km})$ are provided on each axis.

ler-Lagrange equations were iterated until the cost function ceased to decrease (Fig. 11). There is an RMS error of $0.70 \mathrm{~m} \mathrm{~s}^{-1}$ when the analysis is measured against the actual LES output. The analysis qualitatively reproduces all of the features of the LES, even those very small in scale (Fig. 12). Most of the RMS error accrues in the upper portion of the domain, near and above $2 \mathrm{~km}$ AGL. As demonstrated in the homo- geneous flow cases (section 3b), this region has subcritical look angle differences and therefore collinearity among the radial velocity observations. The analysis is biased toward the first guess in these regions, again representing the underapplication of the innovation in each iteration of the analysis technique.

A series of OSSEs was designed to test the sensitivity of the analysis to the platform motion and scan rate. As 
a)
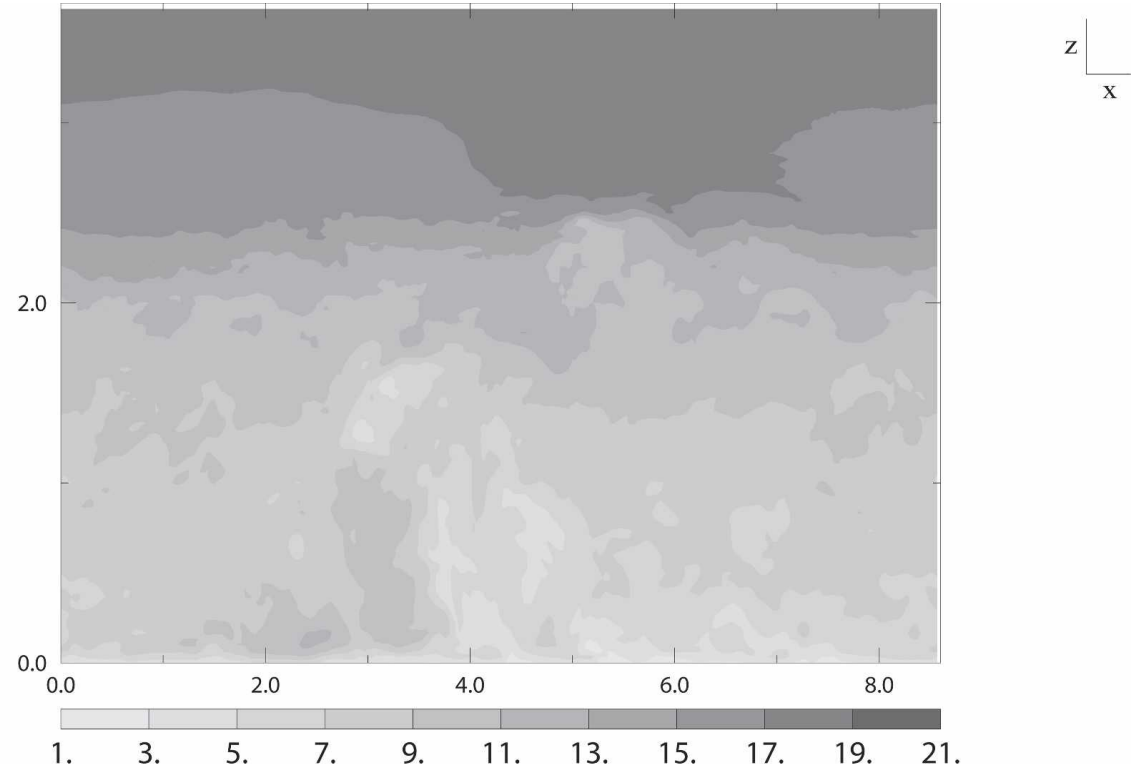

b)
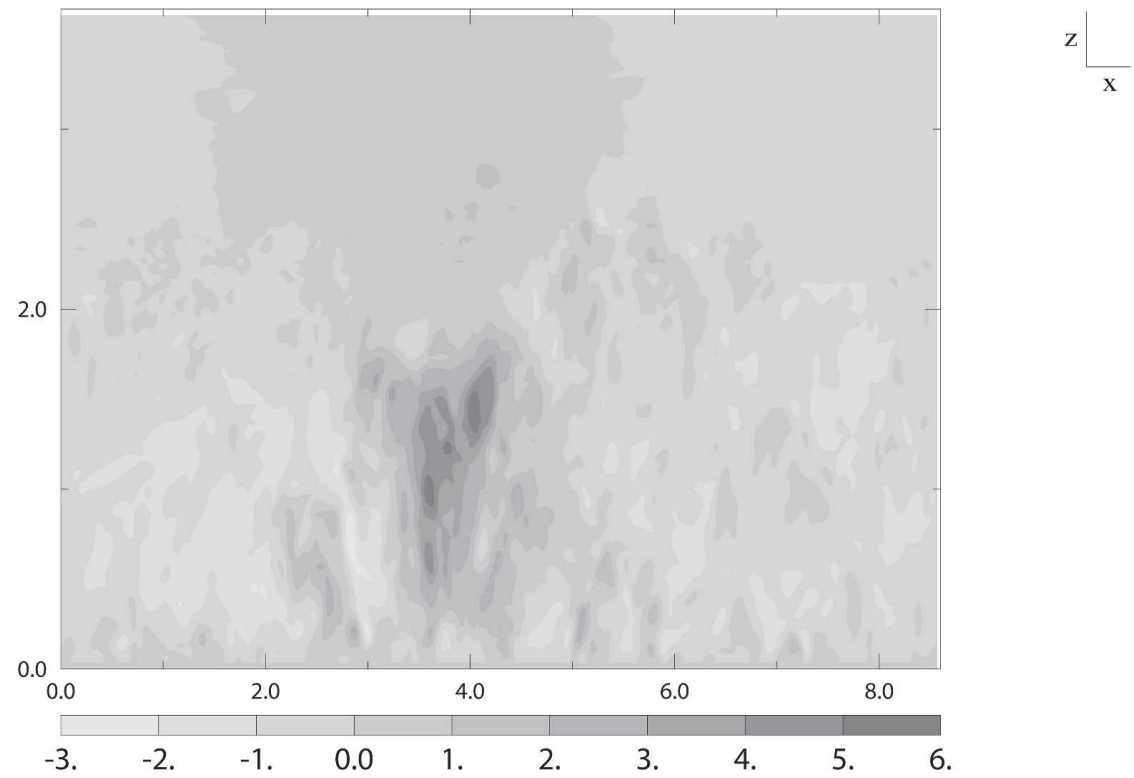

FIG. 10. (a) The $u$-component wind velocity (shaded; $\mathrm{m} \mathrm{s}^{-1}$ ) and (b) vertical velocity (shaded; $\mathrm{m} \mathrm{s}^{-1}$ ) from the large eddy simulation of a highly sheared convective boundary layer. The plane of the cross section is shown in Fig. 9. Distance labels $(\mathrm{km})$ are provided on each axis.

with the homogeneous flow case, the platform speed was allowed to vary from 5 to $30 \mathrm{~m} \mathrm{~s}^{-1}$, and the scan rate was varied from $1^{\circ}$ to $10^{\circ} \mathrm{s}^{-1}$. The results (Fig. 13) are very similar to the homogeneous flow simulations. RMS error increases steadily in proportion with the platform velocity. For slow scan rates, large amounts of error accrue in data-void regions.

\section{d. Sensitivity of the beta term}

In variational Doppler data processing schemes, the $\beta$ term in (1a) represents the relative weight that analy- sis deviations from mass continuity are given to the analysis deviations from observations when computing the cost function for each grid point in the analysis domain. In the dual-Doppler case, there are two observations for each of these points [e.g., the fore and aft antenna looks of the Electra Doppler Radar (ELDORA; Jorgensen et al. 1995)]. Therefore, the value of $\beta$, a constant, solely determines the relative weight of observational and continuity constraints. However, in this pseudo-multiple-Doppler case, any number of observations may exist at each grid point 


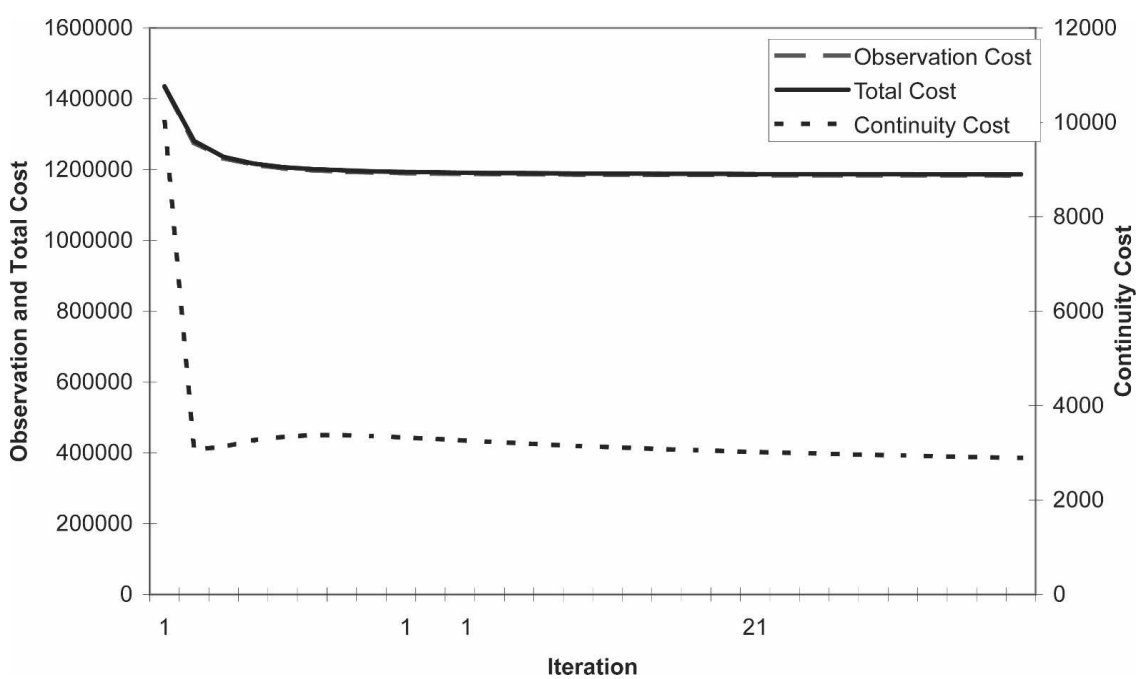

FIG. 11. Cost function $\left(\mathrm{m}^{2} \mathrm{~s}^{-2}\right)$ contribution of observational and continuity error, and total cost function for the first 30 iterations of the LES OSSE. The platform velocity is $15 \mathrm{~m} \mathrm{~s}^{-1}$ and the scan rate is $1.5^{\circ} \mathrm{s}^{-1}$.

[depending on the strategy used; up to a few hundred in this study (e.g., Fig. 6)]. Therefore, in (1a), $\beta$ and $m$ control the relative weights for the constraints. Consequently, mass continuity receives almost no weight for high-observation grid points as it is effectively weighted as one observation. The optimal analysis, therefore, is effectively a solution based upon observations alone.

To increase the influence of continuity in the analysis, $\beta$ was modified to scale with the number of observations:

$$
\beta=m(\Delta x)^{2} .
$$

The incorporation of (10) into (1a) effectively serves as a low-pass filter, and the resulting analyses were expected to be smoother as a result.

The new minimization equation was tested with the homogeneous flow OSSE. A platform velocity of 15 $\mathrm{m} \mathrm{s}^{-1}$ and scan rate of $1.5 \mathrm{~m} \mathrm{~s}^{-1}$ are again used. A greatly exaggerated Gaussian error (standard deviation of $6.0 \mathrm{~m} \mathrm{~s}^{-1}$ ) was added to the time series of radial velocity. The resulting analysis with the nominal mass continuity constraint yielded an RMS error of 5.45 $\mathrm{m} \mathrm{s}^{-1}$, a total of that contributed by both the $u$ (Fig. 14a) and $w$ components (Fig. 14c). With the stronger mass continuity constraint (10), the RMS error decreased to $4.01 \mathrm{~m} \mathrm{~s}^{-1}$, again, a total of the $u$ (Fig. 14b) and $w$ components (Fig. 14d). As noted earlier, most of the error was confined to regions of minimal look angle difference forward (following platform motion) of the lowering antenna. The decrease in domain-wide RMS using (10) was expected, as uncorrelated errors in $u$ and $w$ were more strongly damped by the mass continuity constraint. However, further investigation of the subcritical look difference regions reveals that the regularization property of the mass continuity constraint actually deteriorates the analysis when the look count is minimal (Fig. 14, near the top of the domain) and greatly improves the analysis where the look count is adequate (Fig. 14, lower portion of domain).

\section{Summary and discussion}

A variational pseudo-multiple-Doppler data analysis technique has been developed for use with mobile ground-based Doppler radars. Using a rolling RHI technique, the radar collects a time series of radial velocity data in the vertical plane common to the motion of the radar. Consequently, an overlap of coverage occurs, and individual radar looks can be assumed to be taken simultaneously from multiple radar platforms. The assumption inherent to this procedure-the stationarity approximation-is more or less valid depending on the scanning strategy used and the minimum time scales of motion one wishes to resolve.

A series of OSSEs was executed to test thoroughly the accuracy of the derived analysis equations and to explore the sensitivity of the procedure to the userdefined radar controls, specifically the vehicle velocity and the vehicle antenna rotation rate. OSSEs derived from a homogeneous flow field (with typical random observational error applied) reveal that the technique is very accurate at reproducing the true flow in most cases. As with traditional dual-Doppler techniques, this particular method is weakest in regions where there is a 
a)
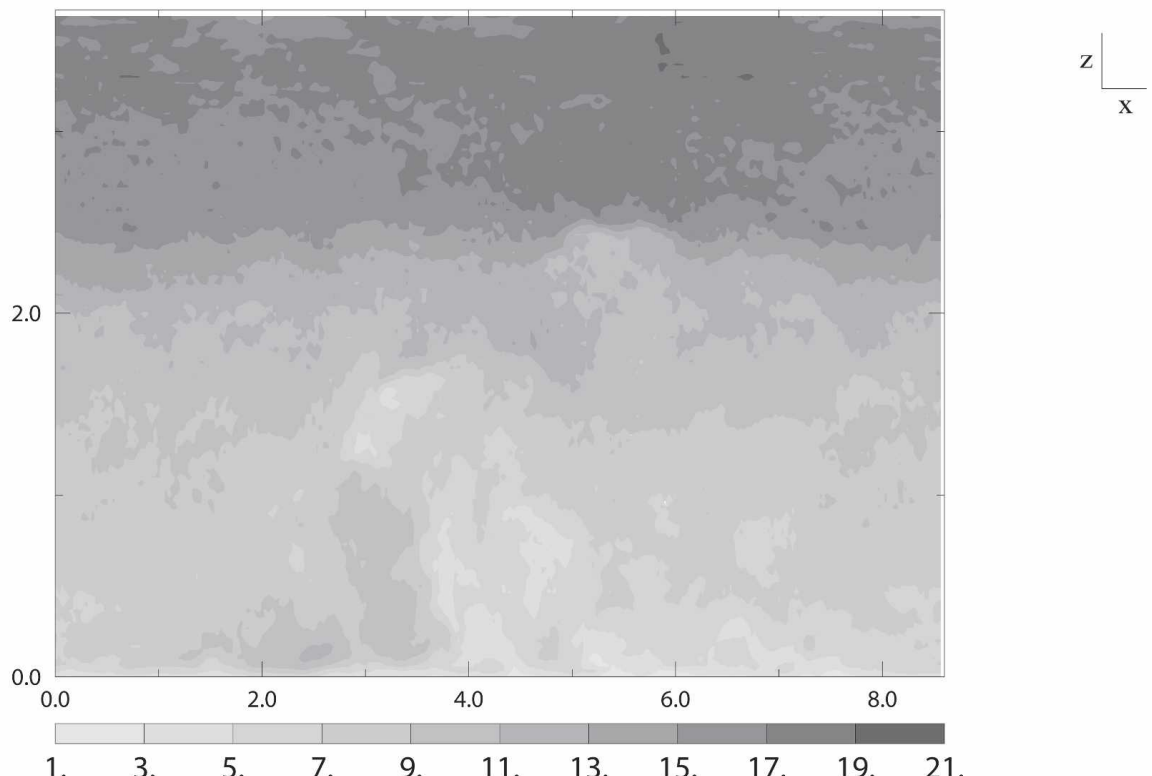

b)
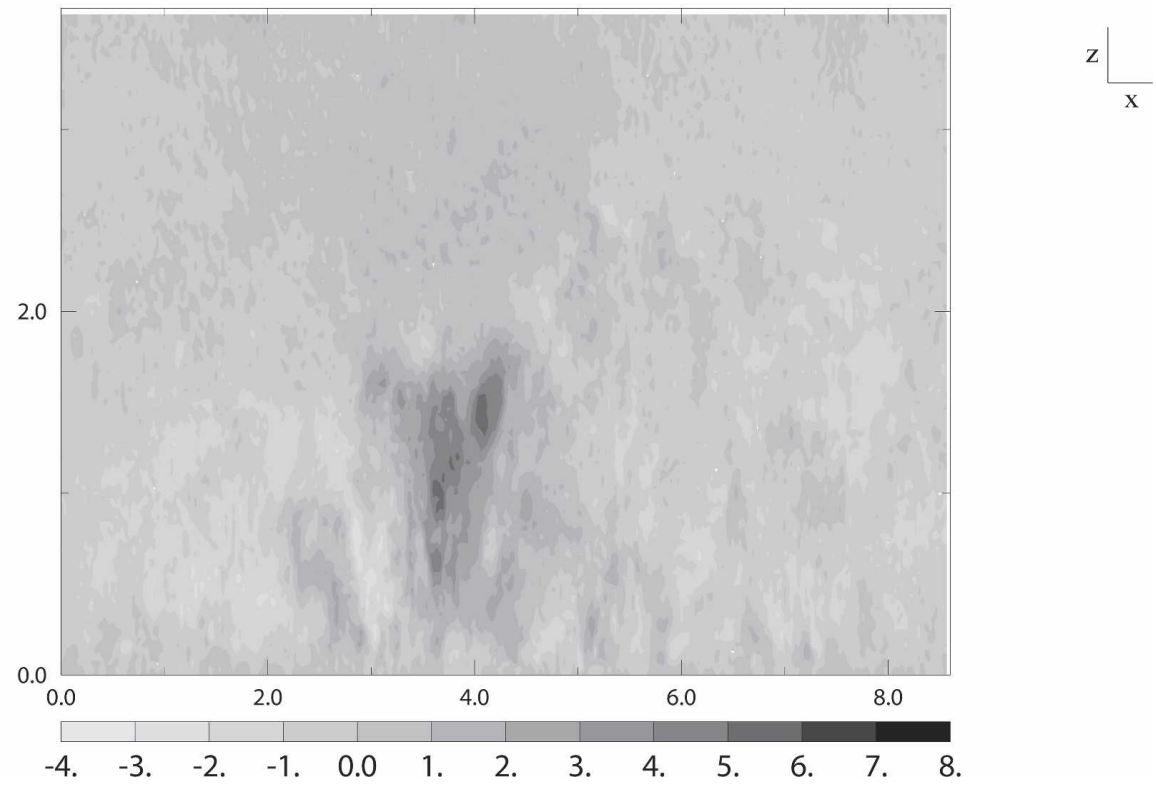

FIG. 12. Same as in Fig. 10, but the fields are derived from the LES OSSE with a platform velocity of $15 \mathrm{~m} \mathrm{~s}^{-1}$, a scan rate of $1.5^{\circ} \mathrm{s}^{-1}$, and a Gaussian observational error of standard deviation $1.0 \mathrm{~m} \mathrm{~s}^{-1}$ applied.

high degree of collinearity among the observations, especially when the maximum difference look angle is under $10^{\circ}$. In these situations, the analysis is biased toward the first guess, representing an underapplication of the observational discrepancy in each analysis iteration. For the rolling RHI strategy, the regions of inadequate look angle differences are naturally located in the upper portion of the domain. The exact altitude depends on the typical range of the radar platform. Using the UMass W-band radar as an example (typical clear-air range of 2-3 km), the look angle difference restriction is of limited importance for the resolution of typical boundary layer structures, such as surface boundaries (e.g., fronts, drylines).

Care must be taken when selecting the platform velocity for data collection. As shown in the OSSEs, too high of a translation speed will necessarily result in data-void regions in the domain. The resulting analysis will therefore be strongly biased toward the first guess, with some information transported in (via mass conti- 


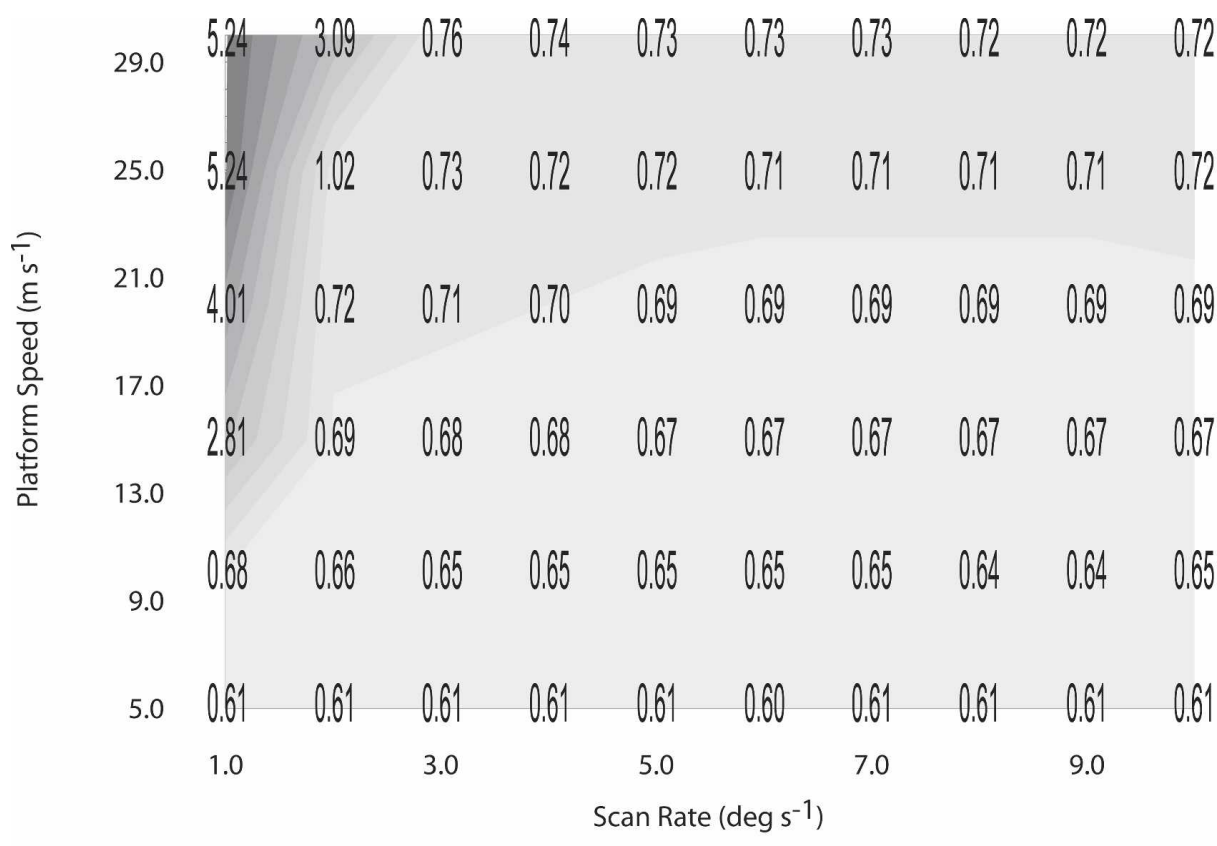

$\begin{array}{lllllllllll}0.2 & 0.7 & 1.2 & 1.7 & 2.2 & 2.7 & 3.2 & 3.7 & 4.2 & 4.7 & 5.2\end{array}$

FIG. 13. Total RMS error (shading; $\mathrm{m} \mathrm{s}^{-1}$ ) of the synthesized wind for the LES OSSE as a function of platform velocity $\left(\mathrm{m} \mathrm{s}^{-1}\right)$ and scan rate $\left({ }^{\circ} \mathrm{s}^{-1}\right)$. Specific RMS error values are included. A random error with standard deviation $1.0 \mathrm{~m} \mathrm{~s}^{-1}$ was applied to radial velocity data for these simulations.

nuity) from data-rich regions with each analysis iteration.

Likewise, the antenna rotation rate is of importance in producing an accurate analysis. Increasing the antenna rotation rate can help reduce or eliminate datavoid regions and also will increase the independence of the radial velocity observations, thereby mitigating the deleterious effects of collinearity. However, the sampling rate, beamwidth, and pulse length of the data collection must be weighed in the decision of scan rate, as too fast of a motion will decrease the density and accuracy of observations. Assuming completely random error, a larger number of observations at a point is desired to resolve the true observational signal, as the noise will largely be reduced through the summation in the cost function.

Central to any pseudo-dual- or pseudo-multipleDoppler synthesis procedure is the stationarity assumption. For standard airborne pseudo-dual-Doppler analysis algorithms, where there are two radars systematically scanning fore and aft of a plane normal to the aircraft, the accuracy of the assumption is a simple function of range. More time must elapse for the pair of looks at distant targets. With the method developed in this paper, the accuracy of the assumption is more complex as, for any given portion of the domain, the tem- poral sampling rate is a two-dimensional function. The assumption is least restrictive in the portion of the scan that is above and just behind (i.e., opposite the platform motion) where the antenna points vertically. This region accumulates the most looks in a short amount of time. Further, the angle difference between the looks is larger, providing for a more accurate analysis.

Though this technique is specifically designed for the incorporation of rolling RHIs in the determination of flow in a vertical plane, where cross-plane horizontal divergence is negligible, the same principle can be applied to a rolling plan position indicator (PPI) data collection for the synthesis of horizontal winds on a level plane, subject to the constraint of nondivergence in the vertical plane. Provided the stationarity assumption is considered in the context of radar scanning strategy and the desired resolvable scales of motion, this technique provides a versatile and cost-effective method for determining boundary layer winds from a single, mobile, clear-air Doppler radar.

Acknowledgments. This work was supported by National Science Foundation (NSF) Grants ATM9912097, ATM-0241037, and ATM-0124068 and was part of the first author's doctoral dissertation at the 

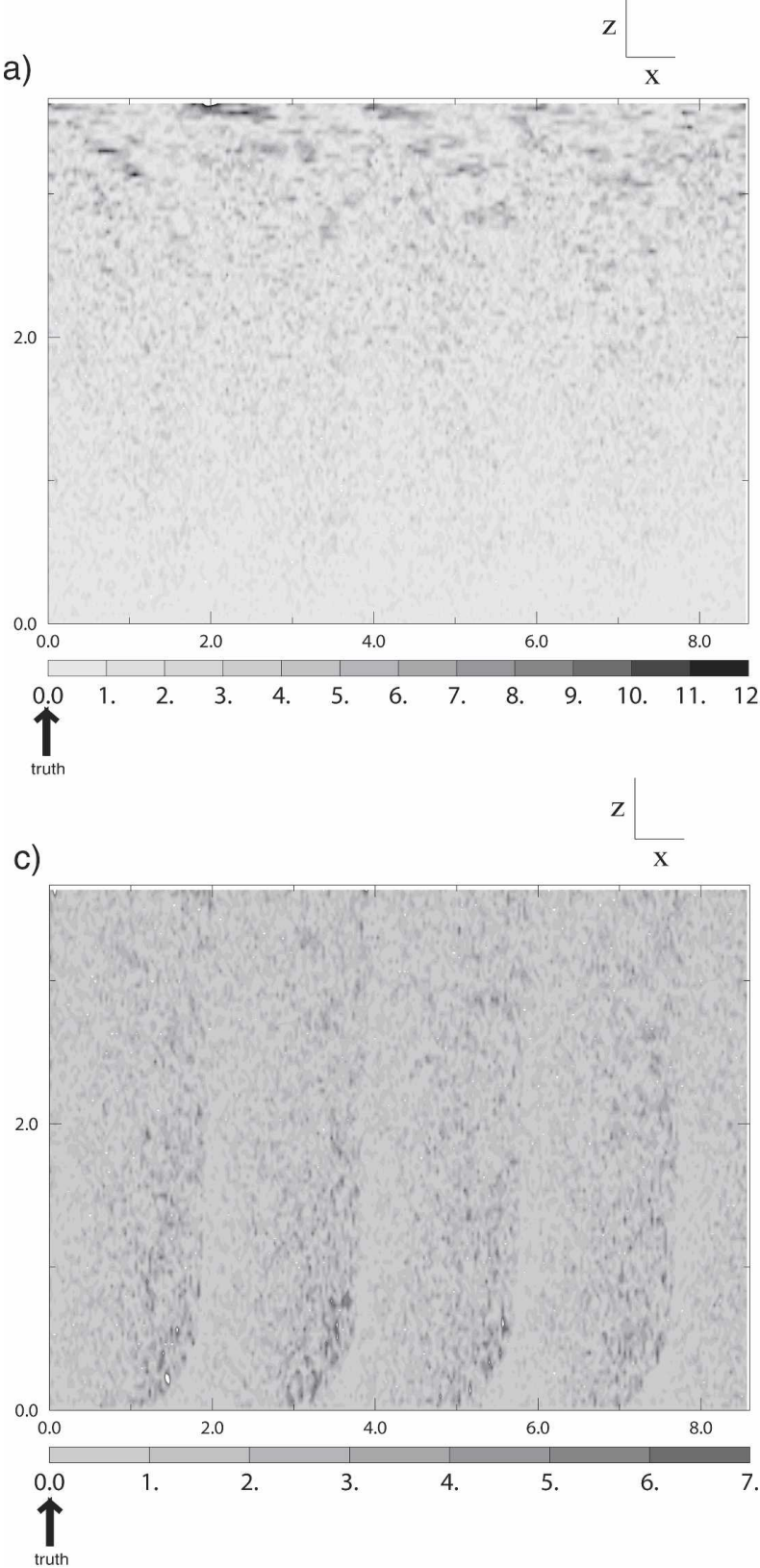

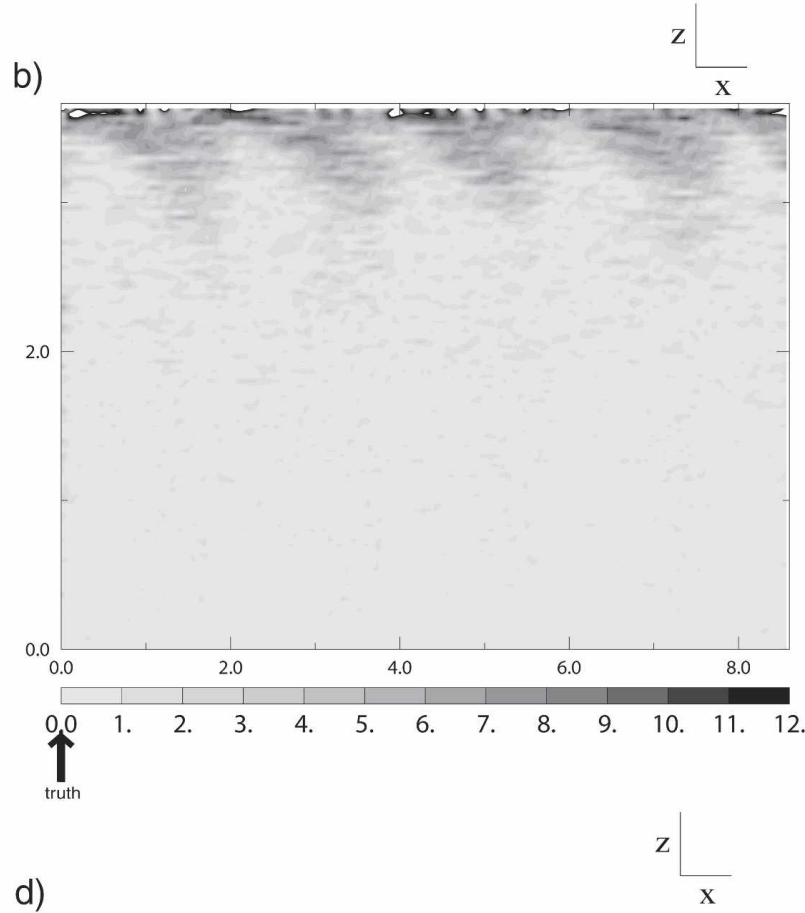

d)

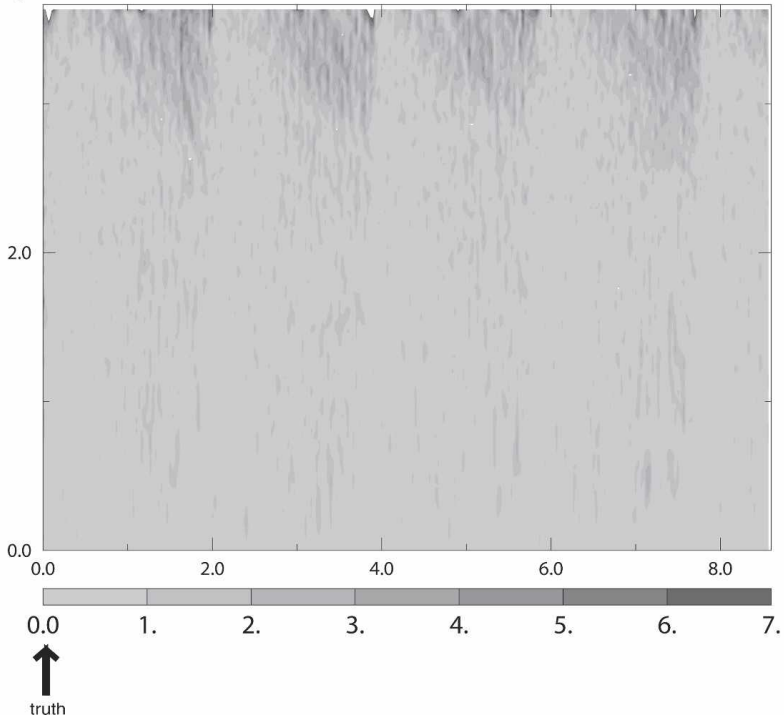

FIG. 14. (a), (b) The $u$-component and (c), (d) $w$-component absolute wind velocity error (shaded; $\mathrm{m} \mathrm{s}^{-1}$ ) from a homogeneous flow OSSE with a platform velocity of $15 \mathrm{~m} \mathrm{~s}^{-1}$, a scan rate of $1.5^{\circ} \mathrm{s}^{-1}$, and an applied observational error of $6.0 \mathrm{~m} \mathrm{~s}^{-1}$. Analysis parameter $b$ is equal to $(\Delta x)^{2}$ in (a) and (c) and equal to $\mathrm{m}(\Delta x)^{2}$ in (b) and (d). Distance labels (km) are provided on each axis.

University of Oklahoma. We are in debt to Bart Geerts, Carl Hane, Alan Shapiro, David Stensrud, Baxter Vieux, and Conrad Ziegler for their constructive comments that have improved this work. We thank David Dowell for useful conversations on variational radar data processing. Ming Xue assisted in the use of ZXPLOT, which was used to generate the analysis figures. We also appreciate the computer assistance from
Mark Laufersweiler at the University of Oklahoma, School of Meteorology.

\section{APPENDIX}

\section{Data Processing Methodology}

The raw UMass data were subjected to preanalysis processing to remove known errors. The first correction made was to eliminate radar echoes with low returned 


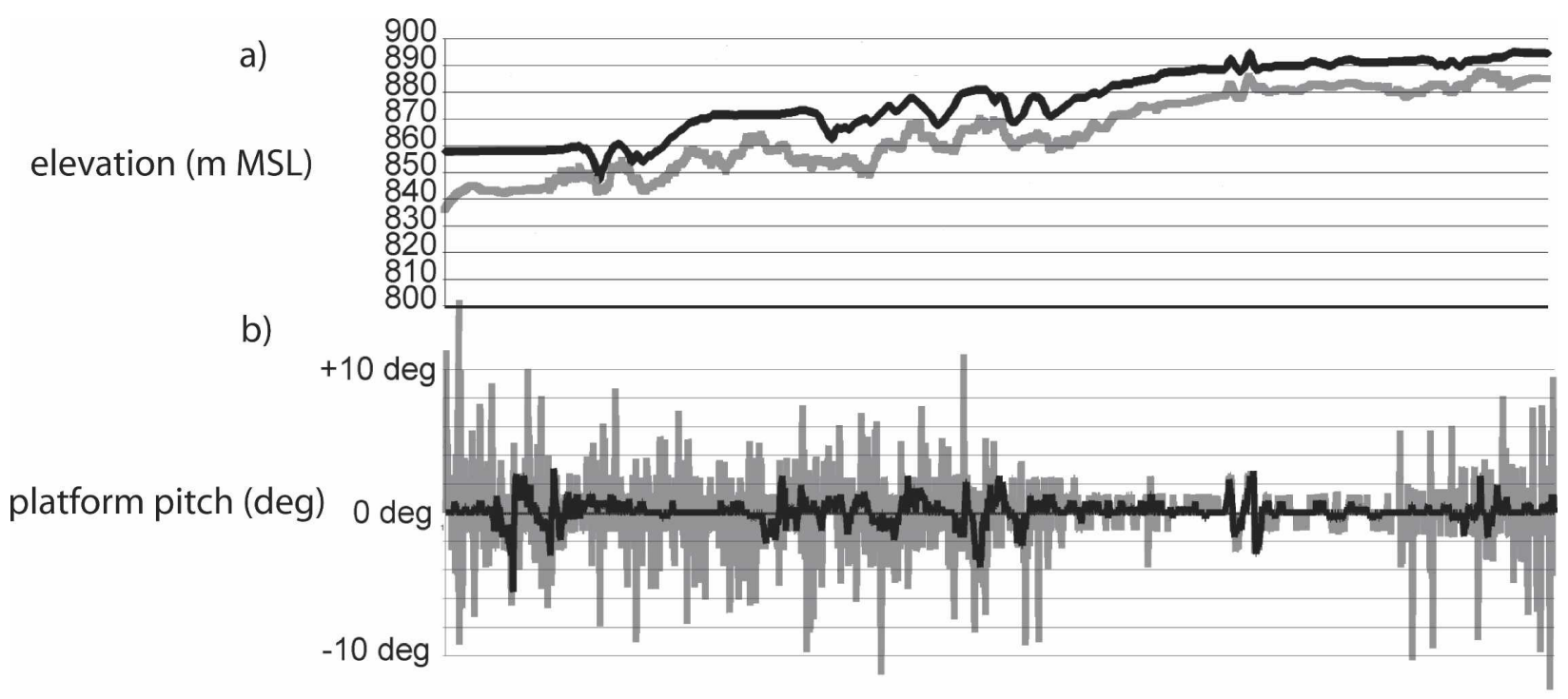

time

FIG. A1. (a) Traces of elevation (m MSL; scale to left) from GPS (gray line) and the DEM (black line) for a representative data collection during IHOP. (b) Traces of pitch ( ${ }^{\circ}$; scale to left) calculated from GPS (gray line) and the DEM (black line).

power, ${ }^{4}$ as velocity estimates are significantly affected by instrument noise in these cases. Solo software (Oye et al. 1995) was used to threshold the data. The remaining velocity data were then unfolded around the Nyquist velocity of $\pm 15.8 \mathrm{~m} \mathrm{~s}^{-1}$.

To transform the measured velocities from a platform- to a ground-relative reference frame, both the magnitude and position of the velocity values had to be altered. GPS measurements of platform position and velocity were recorded at 1 -s intervals during the data collection. The recorded translational velocity was subtracted from each ray in the velocity time series to make the magnitude ground relative.

Using the recorded GPS position and radar elevation, each range element in every ray was mapped to a specific point in Cartesian space using the following geometric formula (in meters):

$$
\begin{aligned}
& \chi=\chi_{\text {start }}+(15 n-7.5) \cos (\alpha) \text { and } \\
& z=z_{\text {start }}+\delta_{\text {elevation }}+(15 n-7.5) \sin (\alpha),
\end{aligned}
$$

where $n$ is the range gate number, $\alpha$ is the platformrelative elevation angle, and $\delta_{\text {elevation }}$ is the correction for the platform's elevation above the reference height

\footnotetext{
${ }^{4}$ The UMass W-band system does not record actual power of return. Therefore, a mock returned power field was created by applying a range correction to reflectivity. The threshold for data removal was subjectively chosen but applied consistently over the entire domain.
}

$\left(z_{\text {start }}\right)$. The decimal residual from (A1) and (A2) was rounded to yield the $x$ and $z$ location of the grid point.

Since the elevation angles were platform relative, a correction factor was included to account for the pitch angle of the platform (i.e., if the platform was tilted uphill or downhill). GPS elevation data were initially considered for this task, but these data were too noisy to carry out the calculation accurately (Fig. A1). Therefore, 30-m resolution digital elevation models (DEMs) from the U.S. Geological Survey (USGS) were introduced. A comparison of pitch calculated from the DEM and GPS elevation data (Fig. A1) reveals a much smoother and representative pitch for the former method.

Once the proper pitch was determined, the $x$ and $z$ gridpoint values for each ray of velocity data were altered. For a westward (eastward) pointed vehicle/ eastward (westward) pointed radar

$$
\Delta X_{\text {adjustment }}=\left\{\begin{array}{lll}
-\Delta X_{\text {uncorrected }} \sin \theta & \text { for } & +\theta(-\theta) \\
\Delta X_{\text {uncorrected }} \sin \theta & \text { for } & -\theta(+\theta)
\end{array}\right\} \text { and }
$$

$\Delta Z_{\text {adjustment }}=-(+) \Delta Z_{\text {uncorrected }} \sin \theta$

where $\theta$ is the pitch angle (positive $\theta$ denotes an uphill pitch for a westward-moving radar), $\Delta X_{\text {uncorrected }}$ and $\Delta Z_{\text {uncorrected }}$ are the original departures of the gridpoint 
a)

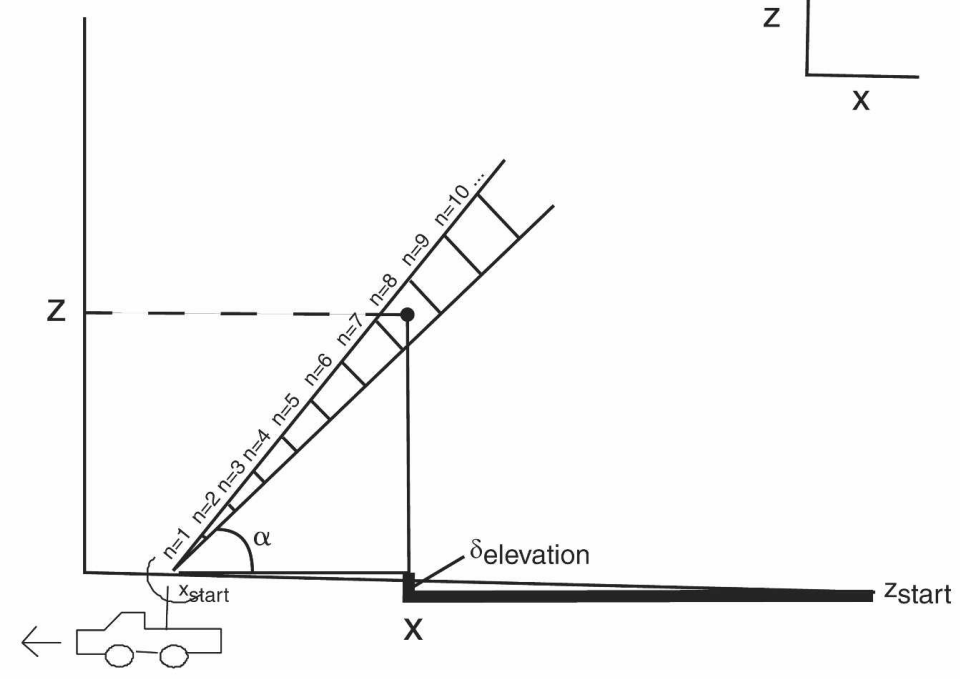

b)

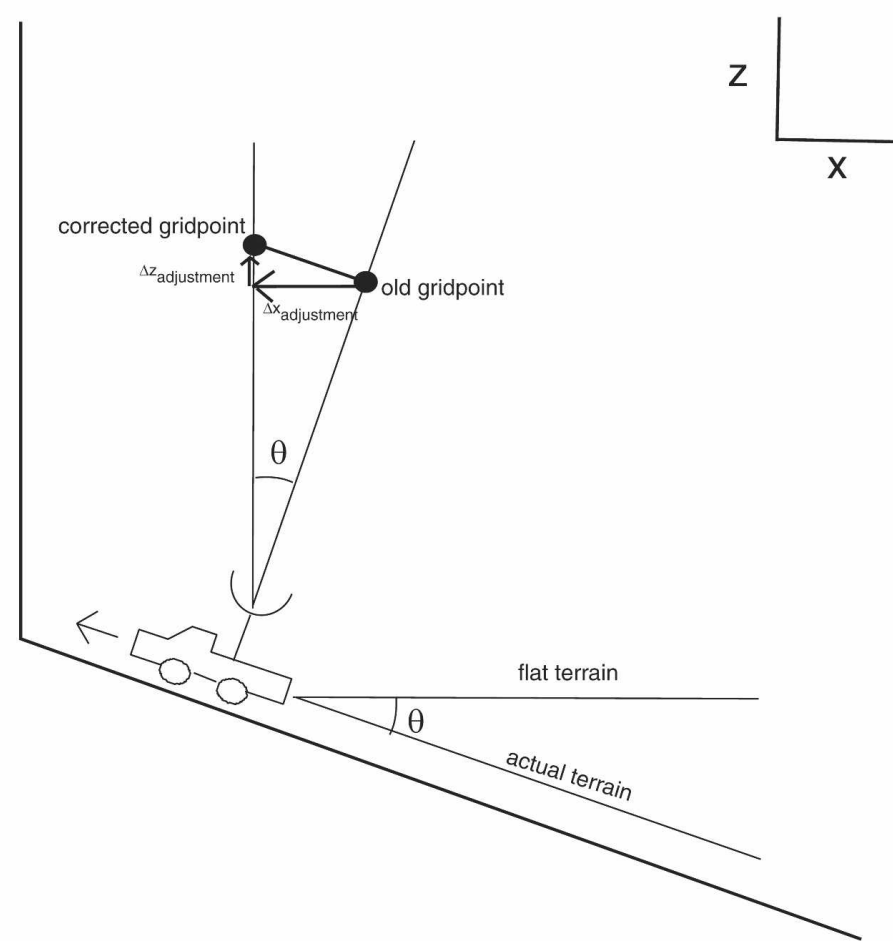

FIG. A2. (a) A schematic illustrating the assignment of radial velocity observations to grid points in the domain [see (A1) and (A2)], and (b) a schematic illustrating the slope correction described in (A3) and (A4).

position from the position of the radar platform, and $\Delta X_{\text {adjustment }}$ and $\Delta Z_{\text {adjustment }}$ are the corrected versions of the same value (Fig. A2).

A dynamically allocated linked list was introduced to store the gridded reflectivity and radial velocity values. For each cell of each ray, reflectivity, radial velocity, and the look angle (platform pitch adjusted) were stored for input to the analysis.

\section{REFERENCES}

Alexander, C. R., and J. Wurman, 2005: The 30 May 1998 Spencer, South Dakota, storm. Part I: The structural evolution and environment of the tornadoes. Mon. Wea. Rev., 133, 72-97.

Atkins, N. T., R. M. Wakimoto, and T. M. Weckwerth, 1995: Observations of the sea-breeze front during CaPE. Part II: DualDoppler and aircraft analysis. Mon. Wea. Rev., 123, 944-969. _ — _ and C. L. Ziegler, 1998: Observations of finescale 
structure of a dryline during VORTEX 95. Mon. Wea. Rev., 126, 525-550.

Biggerstaff, M. I., and R. A. Houze Jr., 1993: Kinematics and microphysics of the transition zone of the 10-11 June 1985 squall line. J. Atmos. Sci., 50, 3091-3110.

Bluestein, H. B., and W. P. Unruh, 1989: Observations of the wind field in tornadoes, funnel clouds, and wall clouds with a portable Doppler radar. Bull. Amer. Meteor. Soc., 70, 1514-1525.

— C. C. Weiss, and A. L. Pazmany, 2004a: The vertical structure of a tornado near Happy, Texas, on 5 May 2002: Highresolution, mobile, W-band, Doppler radar observations. Mon. Wea. Rev., 132, 2325-2337.

_ — - and - 2004b: Doppler radar observations of dust devils in Texas. Mon. Wea. Rev., 132, 209-224.

Bousquet, O., and M. Chong, 1998: A multiple-Doppler synthesis and continuity adjustment technique (MUSCAT) to recover wind components from Doppler radar measurements. J. Atmos. Oceanic Technol., 15, 343-359.

Brandes, E. A., 1977: Flow in severe thunderstorms observed by dual-Doppler radar. Mon. Wea. Rev., 105, 113-120.

_ R. R. Davies-Jones, and B. C. Johnson, 1988: Streamwise vorticity effects on supercell morphology and persistence. $J$. Atmos. Sci., 45, 947-963.

Braun, S. A., and R. A. Houze Jr., 1994: The transition zone and secondary maximum of radar reflectivity behind a midlatitude squall line: Results retrieved from Doppler radar data. $J$. Atmos. Sci., 51, 2733-2755.

Conzemius, R. J., and E. Fedorovich, 2006: Dynamics of sheared convective boundary layer entrainment. Part I: Methodological background and large eddy simulations. J. Atmos. Sci., 63, 1151-1178.

Dowell, D. C., and H. B. Bluestein, 1997: The Arcadia, Oklahoma, storm of 17 May 1981: Analysis of a supercell during tornadogenesis. Mon. Wea. Rev., 125, 2562-2582.

— , and — 2002: The 8 June 1995 McLean, Texas, storm. Part I: Observations of cyclic tornadogenesis. Mon. Wea. Rev., 130, 2626-2648.

_ , and A. Shapiro, 2003: Stability of an iterative dual-Doppler wind synthesis in Cartesian coordinates. J. Atmos. Oceanic Technol., 20, 1552-1559.

- H. B. Bluestein, and D. P. Jorgensen, 1997: Airborne Doppler radar analysis of supercells during COPS-91. Mon. Wea. Rev., 125, 365-383.

Gal-Chen, T., and R. A. Kropfli, 1984: Buoyancy and pressure perturbations derived from dual-Doppler radar observations of the planetary boundary layer: Applications for matching models with observations. J. Atmos. Sci., 41, 3007-3020.

Gao, J., M. Xue, A. Shapiro, and K. K. Droegemeier, 1999: A variational method for the analysis of three-dimensional wind fields from two Doppler radars. Mon. Wea. Rev., 127, 21282142 .

- - , K. Brewster, and K. K. Droegemeier, 2004: A threedimensional variational data analysis method with recursive filter for Doppler radars. J. Atmos. Oceanic Technol., 21, $457-469$.

Hane, C. E., and P. S. Ray, 1985: Pressure and buoyancy fields derived from Doppler radar data in a tornadic thunderstorm. J. Atmos. Sci., 42, 18-35.
Johnson, K. W., P. S. Ray, B. C. Johnson, and R. P. Davies-Jones, 1987: Observations related to the rotational dynamics of the 20 May 1977 tornadic storms. Mon. Wea. Rev., 115, 24632478.

Jorgensen, D. P., T. J. Matejka, and J. D. DuGranrut, 1995: Multibeam techniques for deriving wind fields from airborne Doppler radars. J. Meteor. Atmos. Phys., 58, 83-104.

Kessinger, C. J., P. S. Ray, and C. E. Hane, 1987: The Oklahoma squall line of 19 May 1977. Part I: A multiple Doppler analysis of convective and stratiform structure. J. Atmos. Sci., 44, 2840-2865.

Lee, W.-C., B. J.-D. Jou, P.-L. Chang, and S.-M. Deng, 1999: Tropical cyclone kinematic structure retrieved from singleDoppler radar observations. Part I: Interpretation of Doppler velocity patterns and the GBVTD technique. Mon. Wea. Rev., 127, 2419-2439.

LeMone, M. A., 1973: The structure and dynamics of horizontal roll vortices in the planetary boundary layer. J. Atmos. Sci., 30, 1077-1091.

Oye, R., C. K. Mueller, and S. Smith, 1995: Software for radar translation, visualization, editing, and interpolation. Preprints, 27th Conf. on Radar Meteorology, Vail, CO, Amer. Meteor. Soc., 359-361.

Ray, P. S., C. L. Ziegler, W. Bumgarner, and R. J. Serafin, 1980: Single- and multiple-Doppler radar observations of tornadic storms. Mon. Wea. Rev., 108, 1607-1625.

— D. P. Jorgensen, and S.-L. Wang, 1985: Airborne Doppler radar observations of a convective storm. J. Appl. Meteor., 24, 687-698.

Reinking, R. F., R. J. Doviak, and R. O. Gilmer, 1981: Clear-air roll vortices and turbulent motions as detected with an airborne gust probe and dual-Doppler radar. J. Appl. Meteor., 20, 678-685.

Sasaki, Y., 1970: Some basic formalisms in numerical variational analysis. Mon. Wea. Rev., 98, 875-883.

Shapiro, A., and J. J. Mewes, 1999: New formulations of dualDoppler wind analysis. J. Atmos. Oceanic Technol., 16, 782792.

Wakimoto, R. M., W. C. Lee, H. B. Bluestein, C. H. Liu, and P. H. Hildebrand, 1996: ELDORA observations during VORTEX 95. Bull. Amer. Meteor. Soc., 77, 1465-1481.

Weckwerth, T. M., J. W. Wilson, R. M. Wakimoto, and N. A. Crook, 1997: Horizontal convective rolls: Determining the environmental conditions supporting their existence and characteristics. Mon. Wea. Rev., 125, 505-526.

- and Coauthors, 2004: An overview of the International $\mathrm{H}_{2} \mathrm{O}$ Project (IHOP_2002) and some preliminary highlights. Bull. Amer. Meteor. Soc., 85, 253-277.

Weiss, C. C., and H. B. Bluestein, 2002: Airborne pseudo-dual Doppler analysis of a dryline-outflow boundary intersection. Mon. Wea. Rev., 130, 1207-1226.

$\longrightarrow$, - - and A. L. Pazmany, 2006: Finescale radar observations of the 22 May 2002 dryline during the International $\mathrm{H}_{2} \mathrm{O}$ Project (IHOP). Mon. Wea. Rev., 134, 273-293.

Wurman, J., and S. Gill, 2000: Finescale radar observations of the Dimmitt, Texas (2 June 1995), tornado. Mon. Wea. Rev., 128, 2135-2164. 